\title{
Sulfamethoxazole and isoproturon degradation and detoxification by a laccase-mediator system: Influence of treatment conditions and mechanistic aspects
}

\author{
Jonas Margot $^{\mathrm{a}, *}$, Pierre-Jean Copin ${ }^{\mathrm{b}}$, Urs von Gunten ${ }^{\mathrm{a}, \mathrm{c}}$, D.A. Barry ${ }^{\mathrm{a}}$, Christof Holliger $^{\mathrm{a}}$ \\ a School of Architecture, Civil and Environmental Engineering (ENAC), Ecole Polytechnique Fédérale de Lausanne (EPFL), Station 2, 1015 Lausanne, \\ Switzerland \\ ${ }^{\mathrm{b}}$ Faculty of Geosciences and the Environment, University of Lausanne, 1015 Lausanne, Switzerland

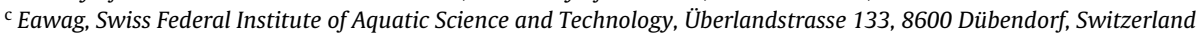

\section{A R T I C L E I N F O}

\section{Article history:}

Received 30 January 2015

Received in revised form 14 May 2015

Accepted 9 June 2015

Available online 26 June 2015

\section{Keywords:}

Laccase

Micropollutant

Biotransformation

Enzyme biocatalysis

Wastewater treatment

Modelling

\begin{abstract}
A B S T R A C T
The potential of laccase-mediator systems (LMS) for the removal and detoxification of two wastewater micropollutants, the antibiotic sulfamethoxazole (SMX) and the herbicide isoproturon (IPN), was assessed. The influence of various parameters on micropollutant oxidation rates, such as $\mathrm{pH}$, mediator, enzyme and pollutant concentrations, was investigated with three mediators: $2,2^{\prime}$-azinobis(3-ethylbenzthiazoline-6-sulphonic acid) (ABTS), syringaldehyde (SA) and acetosyringone (AS). Both pollutants were completely transformed within a few hours in presence of laccase and ABTS, as well as, for SMX, in presence of AS or SA. The three mediators were consumed during the reaction (no catalytic reactions observed), at a ratio mediator/pollutant between 1.1 and $16 \mathrm{~mol} / \mathrm{mol}$. Faster oxidation kinetics were observed at lower $\mathrm{pH}$ values, but also higher mediator/pollutant ratios were required. Several transformation products were formed, including cross-coupled products. Product mixtures were always less toxic to algae than untreated pollutants. Finally, a kinetic model that could explain the experimental observations was established. Based on the findings in this study LMS appears to be a promising option to treat concentrated and potentially toxic industrial effluents.
\end{abstract}

(C) 2015 Elsevier B.V. All rights reserved.

\section{Introduction}

The presence of polar organic micropollutants such as pharmaceuticals and pesticides in wastewater, their poor removal in municipal wastewater treatment plants (WWTPs), and their potential impact on aquatic organisms motivate development of new treatment processes able to deal with these substances [1-4]. Bio-oxidation of these pollutants, catalyzed by oxidative enzymes such as laccase, is a potentially attractive treatment option [5]. Laccases, multi-copper oxidases produced by many fungi and bacteria, can oxidize a wide range of pollutants containing phenol and aniline moieties, including several pharmaceuticals and pesticides, requiring only oxygen as a co-substrate [6].

\footnotetext{
* Corresponding author at: EPFL, ENAC, IIE, ECOL, Station 2, 1015 Lausanne, Switzerland. Fax: +41216938035.

E-mail addresses: jonas.margot@epfl.ch (J. Margot), pierre-jean.copin@unil.ch (P.-J. Copin), urs.vongunten@epfl.ch (U. von Gunten), andrew.barry@epfl.ch (D.A. Barry), christof.holliger@epfl.ch (C. Holliger).
}

Many pollutants are recalcitrant to laccase oxidation. One way to increase their range of action is to use redox mediators [7]. Mediators are organic compounds that can be oxidized by laccase to free radicals. As they are less specific, these radicals can oxidize other pollutants and thus increase the spectrum of compounds potentially degraded by these enzymes. Mediators are often described as "electron shuttles" that, once oxidized to radicals by laccase, may be reduced back to their parent compound during the oxidation of a pollutant [8]. This ideal catalytic cycle (Scheme 1), where only oxygen is consumed during pollutant oxidation, is a means to increase the range of action of laccase. The mediator recycling does, however, not always happen and consumption of mediators during the reaction is possible. In this case, the term "laccase enhancer" is a better descriptor [9]. Nevertheless, mediators or enhancers notably widen the substrate range of laccases. Despite several studies on laccase-mediator systems (LMS) for micropollutant removal in wastewater [10-14], the mechanistic aspects of the kinetics of pollutant oxidation, the fate of the mediator during the reaction, and the conditions required for an optimal pollutant oxidation are not completely understood. 


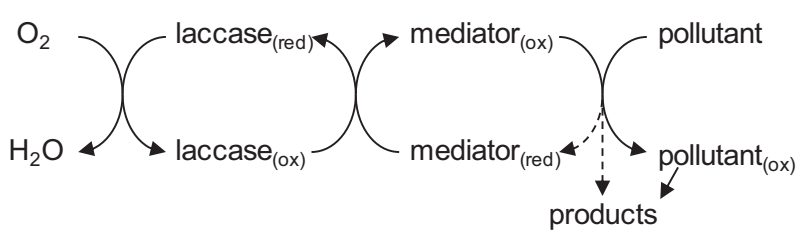

Scheme 1. Ideal laccase-mediator reaction model.

A variety of organic compounds may act as mediators, as long as they can be oxidized by laccase and the free radical formed is stable enough to diffuse away from the enzymatic pocket. Furthermore, the reduction potential has to be high enough to oxidize a target compound [15]. One of the most commonly used synthetic mediators is 2,2'-azino-bis(3-ethylbenzthiazoline6-sulphonic acid) (ABTS) [9]. This compound is oxidized by laccases to a stable radical cation $\mathrm{ABTS}^{\circ+}$ (Fig. S1, Supporting information (SI)) [8]. Natural mediators have also been identified, mostly lignin-derived phenolic compounds, the most effective of which are syringaldehyde (SA) and acetosyringone (AS) [15]. SA and AS have similar structures and are oxidized by laccase to an unstable phenoxy radical (Figs. S1, SI) [16].

To assess the potential of LMS for micropollutant removal in wastewater, two pollutants of environmental concern are investigated in this study: the sulfonamide antibiotic sulfamethoxazole (SMX) and the herbicide isoproturon (IPN) (Figs. S1, SI). Due to its wide consumption and only poor removal in WWTPs, SMX is ubiquitous in municipal wastewater effluents (in average around $200 \mathrm{ngl}^{-1}$ in Switzerland) [17] and may generate risks for sensitive aquatic organisms in the receiving waters [18]. IPN is a herbicide commonly used in urban areas (parks, gardens, cemeteries) and therefore also frequently detected in municipal WWTP effluents [17]. Due to its toxicity at very low concentrations, it was selected as a priority substance by the European Union [19].

The aims of this study were (i) to assess the potential of LMS for SMX and IPN degradation and detoxification with three mediators: ABTS, AS and SA, and (ii) to determine the influence of the operational parameters $(\mathrm{pH}$, laccase, mediator and pollutant concentrations) on LMS-based oxidation kinetics. Based on these experiments (a) optimal conditions for pollutant degradation were identified, (b) mechanistic aspects of LMS-based systems were elucidated, and (c) the potential of LMS for the treatment of micropollutants in wastewater was assessed.

\section{Materials and methods}

\subsection{Chemicals and enzyme}

SMX and IPN (purity $>99 \%$ ), laccase powder from Trametes versicolor (ref. 38.429, Sigma), ABTS diammonium salt, SA, AS, and all other chemicals were purchased from Sigma-Aldrich Chemie $\mathrm{GmbH}$ (Buchs, Switzerland). Stock solutions of SMX (3.95 mM, $1 \mathrm{~g}$ $\left.\mathrm{l}^{-1}\right)$, IPN (4.85 mM, $\left.1 \mathrm{~g} \mathrm{l}^{-1}\right)$, AS (10 mM, $\left.1.96 \mathrm{~g} \mathrm{l}^{-1}\right)$ and SA (10 mM, $\left.1.82 \mathrm{~g} \mathrm{l}^{-1}\right)$, were prepared in pure methanol and stored at $-18^{\circ} \mathrm{C}$. Stock solutions of ABTS ( $\left.10 \mathrm{mM}, 5.14 \mathrm{~g} \mathrm{l}^{-1}\right)$ and laccase $\left(2 \mathrm{~g} \mathrm{l}^{-1}\right)$ were prepared in pure water, stored at $4{ }^{\circ} \mathrm{C}$ and replaced for any new set of experiments. A stock solution of aqueous chlorine $\left(\mathrm{OCl}^{-}\right.$, $8.16 \mathrm{mM}$ ) was prepared by diluting a sodium hypochlorite solution (around 5\%, Sigma) 100 times. The final $\mathrm{OCl}^{-}$concentration was measured at $\mathrm{pH} 10.9$ by spectrophotometry at $292 \mathrm{~nm}$ (extinction coefficient $\epsilon_{292 \mathrm{~nm}}$ of $362 \mathrm{M}^{-1} \mathrm{~cm}^{-1}$ ) [20].

A stock solution of the ABTS radical cation (at $5 \mathrm{mM}$ ) was produced by chemical oxidation of ABTS $(6.9 \mathrm{mM}$ in pure water) with aqueous chlorine $(2.5 \mathrm{mM})$, in acidic conditions $(\mathrm{pH}<5)$, at a slightly under-stoichiometric ratio to avoid potential residual chlorine in the solution [21]. Another solution of ABTS radical cations was produced by ultrafiltration (Vivaspin 20 centrifugation devices, PES, MWCO: $3 \mathrm{kDa}$, from Startorius AG, Göttingen, Germany) of a solution of ABTS $(500 \mu \mathrm{M})$ oxidized by laccase, in order to remove (most of) the enzyme $(>60 \mathrm{kDa})$. The exact ABTS $^{\circ+}$ concentration was determined by spectrophotometry at $420 \mathrm{~nm}$ $\left(\epsilon_{420 \mathrm{~nm}}\right.$ of $\left.36,000 \mathrm{M}^{-1} \mathrm{~cm}^{-1}\right)$ [22].

\subsection{Laccase activity test}

The laccase activity was determined using a colorimetric assay by measuring the oxidation of $0.5 \mathrm{mM}$ ABTS in an oxygen-saturated acetate buffer $(0.1 \mathrm{M})$ at $\mathrm{pH} 4.5$ and $25^{\circ} \mathrm{C}$ as described by Margot et al. [23]. A sample aliquot containing laccase was added to the solution and the increase of absorbance at $420 \mathrm{~nm}$ was monitored with a temperature-controlled spectrophotometer (U3010, Hitachi, Tokyo, Japan). One unit of activity (U) was defined by the oxidation of one $\mu \mathrm{mol}$ of ABTS per min.

\subsection{Micropollutant, mediator and transformation product analyses}

Determinations of SMX, IPN, AS, and SA concentrations were carried out by reverse phase liquid chromatography with a diode-array detector (HPLC-DAD) (LC-2000plus, Jasco, Tokyo, Japan, equipped with Bondapack-C18 column, 15-20 $\mu \mathrm{m}$, $3.9 \mathrm{~mm} \times 300 \mathrm{~mm}$, Waters ${ }^{\mathrm{TM}}$, Milford, USA). Aliquots of $50 \mu \mathrm{l}$ were injected. Separation of the compounds and the transformation products was conducted with a 30 -min gradient, at $1 \mathrm{ml} \mathrm{min}^{-1}$, of pure $\mathrm{H}_{2} \mathrm{O}$ containing $0.1 \%$ acetic acid ( $\mathrm{pH} 3.23$ ) and increasing concentration of methanol (with $0.1 \%$ acetic acid) from 5 to $52 \%$ $(\mathrm{v} / \mathrm{v})$ or 15 to $60 \%$, for SMX, AS and SA, or IPN determination, respectively. The compounds were detected at 268, 305, 305 and $242 \mathrm{~nm}$ for SMX, AS, SA, and IPN, respectively. The limit of quantification (LOQ) was around $0.1 \mathrm{mgl}^{-1}$ (around $0.5 \mu \mathrm{M}$ ), and the accuracy of the measurements (coefficient of variation of 10 injections) was around 1-2\%.

Characterization of the transformation products formed during the laccase-mediated reaction was carried out by HPLC coupled to a mass spectrometer (UPLC-MS). Aliquots of $10 \mu \mathrm{l}$ of each sample were injected in the column (Acquity UPLC system, with a HSS T3 $\left(\mathrm{C}_{18}\right)$ column, $2.1 \times 100 \mathrm{~mm}, 1.8 \mu \mathrm{m}$, Waters), which was eluted at $30^{\circ} \mathrm{C}$ in $20 \mathrm{~min}$ at $0.4 \mathrm{ml} \mathrm{min}^{-1}$ with a mobile phase composed of pure water and methanol, in a gradient mode, from 2 to $95 \%$ methanol. Transformation products were characterized $(\mathrm{m} / \mathrm{z}$ ratio and retention time) and quantified (signal intensity) by MS (Xevo TQ MS, Waters) in scan mode $(40-2000 \mathrm{~m} / \mathrm{z}$, scan time $0.4 \mathrm{~s})$ and a positive electrospray ionization mode (ES+, cone voltage $30 \mathrm{~V}$ ). Based on the retention times, some of the transformation products characterized by MS could be related to transformation products observed by HPLC-DAD, which gave further information about their $\mathrm{UV} /$ visible absorption spectrum.

\subsection{Micropollutant oxidation assay in laccase-mediator systems under various conditions}

Micropollutant oxidation assays were performed at different $\mathrm{pH}$ values (3-9) in citrate or phosphate buffers $(30-40 \mathrm{mM})$ containing the pollutant at around $100 \mu \mathrm{M}\left(20-25 \mathrm{mgl}^{-1}\right)$ and variable concentrations of mediator $(10-1000 \mu \mathrm{M})$. Batch reactions were conducted in 2-ml glass vials containing $1 \mathrm{ml}$ of an oxygensaturated reaction mixture. Reactions were initiated by adding laccase to obtain an initial activity between 100 and $650 \mathrm{U} \mathrm{l}^{-1}$. Vials were incubated in the dark at $25^{\circ} \mathrm{C}$ under static conditions for several hours (usually around $20 \mathrm{~h}$ ). After defined reaction times (every $40-160 \mathrm{~min}$ ), aliquots $(50 \mu \mathrm{l})$ were withdrawn from each vial and directly injected into the HPLC column to 
analyze micropollutant and mediator concentrations. Controls without laccase or without mediators were performed to assess micropollutant degradation by mediators or by laccase alone, respectively. Experiments were typically carried out in duplicate.

Several experiments were performed under various conditions to better understand laccase-mediated reactions: (i) three mediators were tested (namely ABTS, AS and SA) with either SMX or IPN; (ii) for each mediator, degradation kinetics were studied at various $\mathrm{pH}$ values (from 3 to 9), diverse mediator concentrations (from 10 to $1000 \mu \mathrm{M}$ ), various laccase activities (from 100 to $650 \mathrm{U}$ $\mathrm{l}^{-1}$ ), and various pollutants concentrations (from 50 to $150 \mu \mathrm{M}$ ).

For the transformation product analyses by UPLC-MS, lower micropollutants concentrations were used: (i) IPN at $20 \mu \mathrm{M}$ with $500 \mu \mathrm{M}$ ABTS and $560 \mathrm{U}^{-1}$ laccase at $\mathrm{pH}$, and (ii) SMX at $10 \mu \mathrm{M}$ with $50 \mu \mathrm{M}$ mediator (ABTS, AS or SA) and $560 \mathrm{U} \mathrm{l}^{-1}$ laccase at $\mathrm{pH}$ 6 . After defined reaction times (around every hour), $10 \mu \mathrm{l}$ were withdrawn from each vial and directly injected into the UPLCMS to follow the kinetics of transformation product formation. Controls with laccase and mediators without pollutants were also performed.

Dissolved oxygen consumption experiments were conducted in a closed (airtight) cell containing an oxygen probe and $3 \mathrm{ml}$ of reactive solution. The cell was closed just after addition of laccase in an air-oxygen saturated solution, without any headspace.

\subsection{Evaluation of the role of the ABTS radical cation}

The role of the ABTS radical cation $\left(\mathrm{ABTS}^{\circ}\right)$ in the oxidation reaction was assessed by comparing degradation kinetics in solutions containing micropollutants $(100 \mu \mathrm{M})$ and (i) only ABTS $(550 \mu \mathrm{M})$ chemically oxidized by $\mathrm{HOCl}$, (ii) chemically oxidized ABTS $(550 \mu \mathrm{M})$ and laccase $\left(280 \mathrm{U}^{-1}\right)$, (iii) ABTS oxidized by laccase (160-200 $\mu \mathrm{M}$, ultrafiltered) with very low laccase activity $\left(<10 \mathrm{U}^{-1}\right)$, and (iv) ABTS oxidized by laccase $(160-200 \mu \mathrm{M}$, ultrafiltered) with further addition of laccase (200-250 $\mathrm{U} \mathrm{l}^{-1}$ ). These experiments were conducted in duplicate, at pH 5 with IPN and $\mathrm{pH} 5$ or 6 with SMX.

\subsection{Ecotoxicity test}

A growth inhibition assay on the green alga Pseudokirchneriella subcapitata was selected to evaluate the toxicity of the micropollutants before and after treatment with the laccasemediator system, as green algae are among the most sensitive organisms to the herbicide IPN but also to the antibiotic SMX (Ecotoxicity database AiiDA: www.aiida.tools4env.com).

For the toxicity test, mediators (AS and SA) and SMX stock solutions were prepared in pure water, as methanol is toxic to the green algae at the level present in the solutions (50\% growth inhibition at $1 \mathrm{gl}^{-1}(0.125 \% \mathrm{v} / \mathrm{v})$, data not shown).

The samples tested consisted of IPN $(100 \mu \mathrm{M})$ or SMX $(150 \mu \mathrm{M})$ in a citrate-phosphate (20-40 mM) buffer at pH 5 or 6, respectively, with or without reaction during $40 \mathrm{~h}$ (with IPN) or $88 \mathrm{~h}$ (with SMX) at $25^{\circ} \mathrm{C}$ with a mediator concentration of $500 \mu \mathrm{M}$ (either ABTS, AS or SA with SMX and only ABTS with IPN) and laccase $\left(540 \mathrm{Ul}^{-1}\right)$. Controls were performed with each mediator and laccase incubated without pollutant, at the same concentrations. Long reaction times were used to assure complete reaction of the pollutants and stabilisation of the transformation products. These solutions were then diluted 200 times (with IPN) or 20 times (with SMX) in the algae growth medium prior to the toxicity tests to achieve concentrations of pollutants $(0.5$ and $7.5 \mu \mathrm{M}$ for IPN and SMX, respectively) in the algae medium that still allow them to grow [24,25].

The algae growth inhibition test was performed according to the OECD guideline 201 [26] with the green algae Pseudokirchneriella subcapitata (Chlorophyceae ; strain SAG 61.81, from the Culture Collection of Algae, Göttingen, Germany), maintained as described by Valloton et al. [27]. Briefly, exponentially growing algae (initially around 50,000 cells ml-1 in sterile mineral AAP growth medium, $\mathrm{pH} 7.5$ ) were exposed to the diluted samples over a period of $72 \mathrm{~h}$, in an incubation shaker (Infors HT, Bottmingen, Switzerland) at $25^{\circ} \mathrm{C}$ and $90 \mathrm{rpm}$, with continuous illumination $\left(70 \mu \mathrm{mol} \mathrm{m}^{-2} \mathrm{~s}^{-1}\right)$ by cool-white fluorescent lamps. Algae growth was determined as described by Daouk et al. [28] by measuring the optical density at a wavelength of $690 \mathrm{~nm}$ (linearly correlated to the cell density) with a microplate reader $\left(\mathrm{ELx}_{800}{ }^{\mathrm{TM}}\right.$, BioTek ${ }^{\circledR}$ Instruments, Winooski, Vermont) at the beginning and at the end of the test. The growth rate was calculated as the natural logarithmic increase in the optical density over time, and the growth inhibition was then determined by relative comparison of the growth rate of algae exposed to the sample to the one of algae growing in pure mineral media (controls), according to the OECD 201 guideline. Tests were carried out in triplicate, with a coefficient of variation for the growth rates below $16 \%$ and $2.5 \%$ for the samples and the controls, respectively, meeting the validity criteria of the OECD guideline. SMX and IPN were analysed before and after $72 \mathrm{~h}$ of incubation in the samples not treated by laccase-mediator. Less than 3-6\% loss was observed for both compounds, confirming a constant exposure during the test.

\subsection{Reaction modelling of laccase-mediator systems}

Based on the results of the experiments, a kinetic model of laccase-mediator reactions was established, considering Michaelis-Menten type kinetics for laccase/mediator reactions and second-order rate kinetics for mediator/pollutant reactions (see Section 13, SI). The various differential equations were solved numerically with the ode45 solver (variable step Runge-Kutta method) within MATLAB (MathWorks, USA).

\section{Results and discussion}

\subsection{Oxidation of IPN and SMX with various mediators}

IPN or SMX did not react with the enzyme or the mediators alone during the time of incubation (up to $72 \mathrm{~h}$ ) (Fig. S2, SI). Recalcitrance of SMX to laccase oxidation was recently reported [29], although this compound was oxidized by crude Phanerochaete chrysosporium laccase extract in another study [30], possibly due to the presence of other oxidative enzymes or mediators in the extracted solution.

With LMS, IPN was completely oxidized in the presence of ABTS in less than $20 \mathrm{~h}$ at pH 4-6 (Fig. $1 \mathrm{~A}$ ). The two other natural mediators (AS and SA) were on the contrary not able to mediate the oxidation of IPN, even at high concentrations (500 $\mu \mathrm{M}, \mathrm{pH} 5)$ and for long reaction times (up to $96 \mathrm{~h}$ ) (Fig. S2 A, SI).

SMX appeared to be much more reactive to LMS oxidation, with reasonable oxidation rates in presence of ABTS and very fast oxidation (almost complete removal in less than $1 \mathrm{~h}$ ) in the presence of both AS or SA at pH 6 (Fig. 1B-D). Very few studies have been published on SMX oxidation by LMS. Recently, a few studies showed that SMX could be oxidized by laccase in presence of several mediators (1-hydroxybenzotriazole (HTB), syringic acid, AS and SA) [29,31,32]. Oxidation by LMS of other sulfonamides (sulfadimethoxine and sulfamonomethoxine) was also reported [33]. The mechanisms and the conditions for the oxidation of these pollutants by LMS are, however, still largely unknown.

\section{2. $p H$ influence on the oxidation kinetics}

As shown in previous studies [23,34], pH has a strong influence on the laccase activity, with higher activities (for T. versicolor 


\section{A.1 IPN with ABTS}

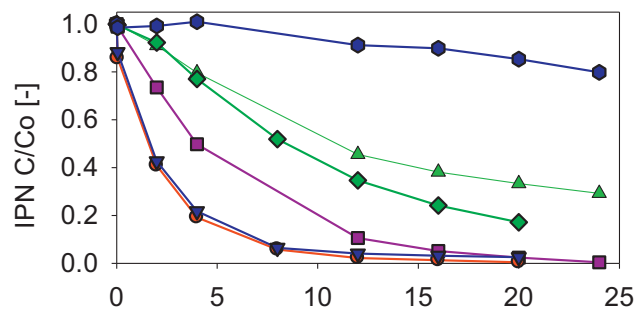

B.1 SMX with ABTS Time [h]

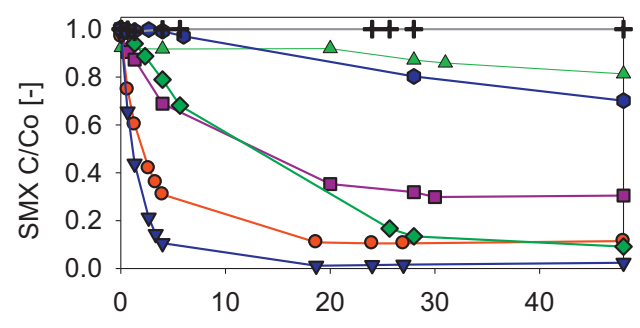

C.1 SMX with SA Time [h]

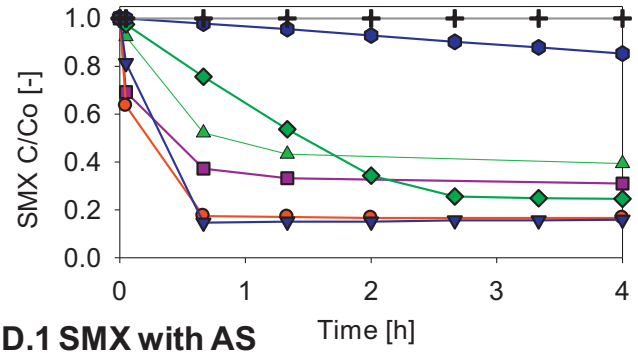

D.1 SMX with AS Time [h]
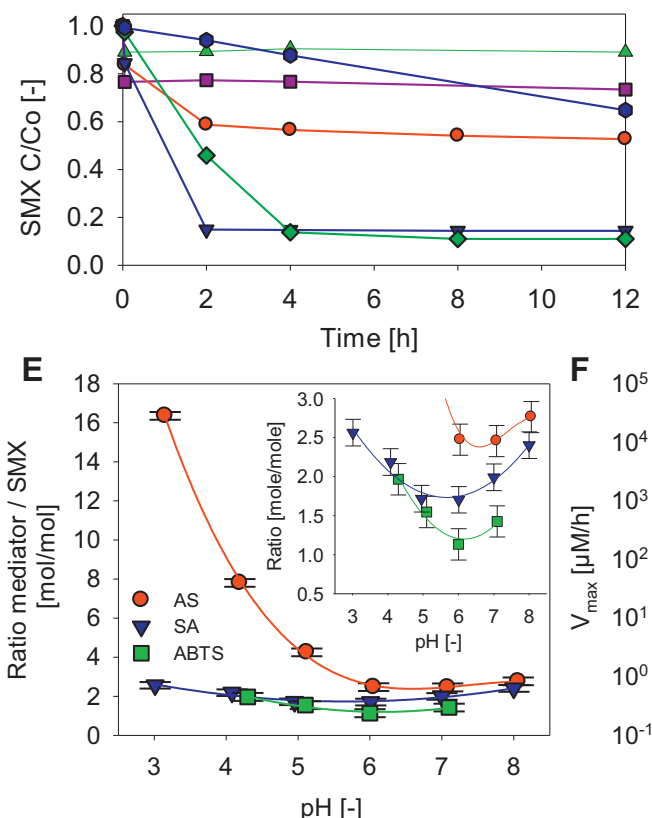

F $10^{5}$
A. 2

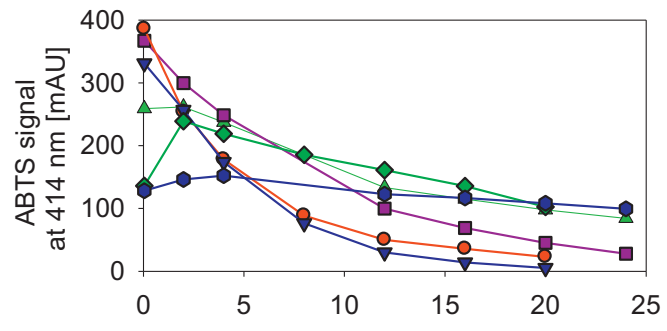

$\triangle \mathrm{pH} 3.2$

$\rightarrow-\mathrm{pH} 4.3$

- $-\mathrm{pH} 5.3$

$\rightarrow-\mathrm{pH} 6.2$

$\diamond \mathrm{pH} 7$.

$\rightarrow \mathrm{pH} 7.9$

\section{B.2}

Time [h]
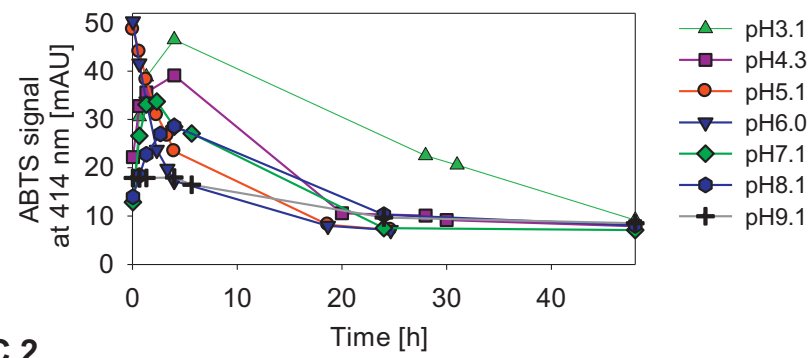

$\rightarrow \mathrm{pH} 4.3$

- $\mathrm{pH} 5.1$

$\rightarrow \mathrm{pH} 6.0$

$\sim \mathrm{pH} 7.1$

$\rightarrow$ pH8.1

$+\mathrm{pH} 9.1$

C. 2
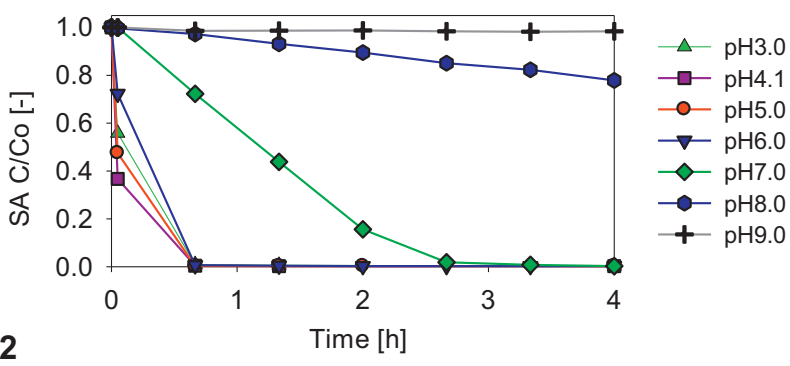

D.2

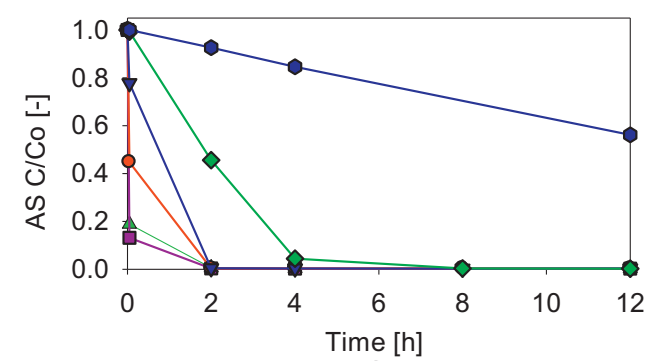

$\triangle \mathrm{pH} 3.1$

$\rightarrow \mathrm{pH} 4.2$

- $-\mathrm{pH} 5.1$

$\rightarrow-\mathrm{pH} 6.1$

$\diamond \mathrm{pH} 7.1$

$\rightarrow \mathrm{pH} 8.1$

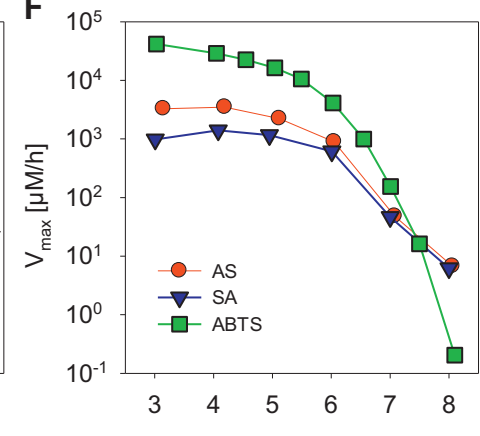

$\mathrm{pH}[-]$

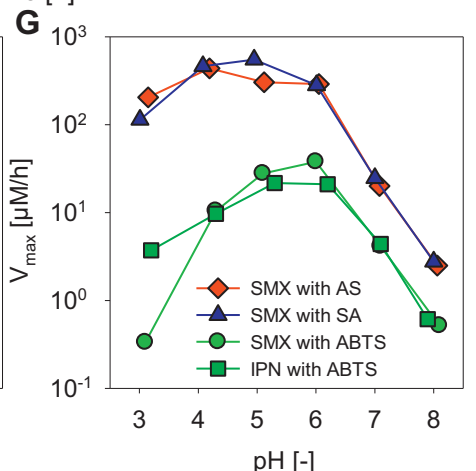

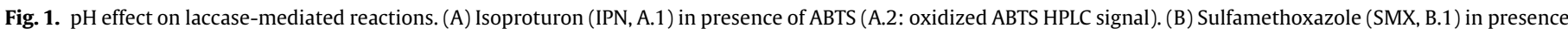

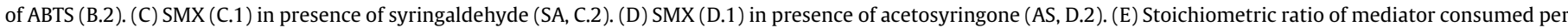

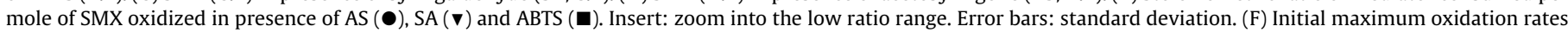

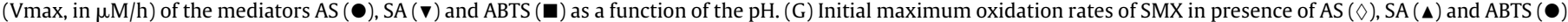

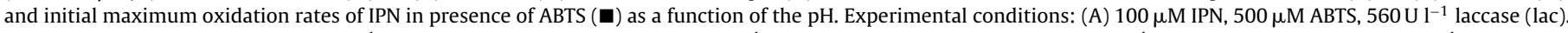

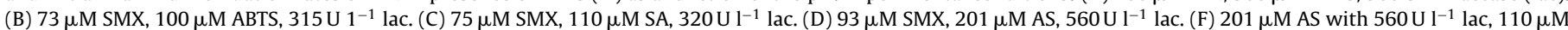

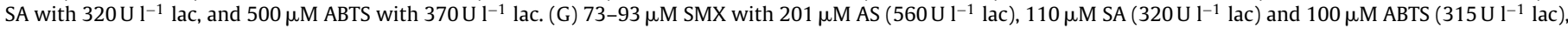
and $100 \mu \mathrm{M}$ IPN with $500 \mu \mathrm{M}$ ABTS (560 $\mathrm{U} \mathrm{l}^{-1} \mathrm{lac}$ ). 
laccase) under acidic conditions ( $\mathrm{pH} \mathrm{4-6)} \mathrm{and} \mathrm{almost} \mathrm{no} \mathrm{activity}$ in alkaline solutions $(\mathrm{pH}>7.5-8)$. It was therefore expected that LMS oxidation would also be strongly influenced by $\mathrm{pH}$, especially during the first stage of the mediator oxidation by laccase. To further elucidate the effect of the $\mathrm{pH}$, experiments were performed in the $\mathrm{pH}$ range from 3 to 9 . As presented in Fig. 1, kinetics of SMX and IPN abatement varied significantly as a function of $\mathrm{pH}$. Fast oxidation of both compounds was observed at $\mathrm{pH}$ 5-6 for all three mediators, with decreasing rates at lower (3-4) or higher (7-8) pHvalues. No significant oxidation was observed at $\mathrm{pH} 9$. The optimal $\mathrm{pH}$ range for IPN and SMX oxidation was around 5-6 (Fig. 1G or Fig. S3, SI), significantly higher than the optimal $\mathrm{pH}$ for mediator oxidation $(\mathrm{pH}<3-4)$ (Fig. 1F). This difference could be related to a higher self-reaction of mediator radicals at lower $\mathrm{pH}$ (produced locally at high concentrations), leading to a decreasing pollutant exposure with reactive species (cf. Section 3.7.5).

\subsection{Mediator consumption and effect of $\mathrm{pH}$ on the ratio mediator/pollutant}

Mediators are often described as electron-shuttles between laccase and the substrate, with catalytic action of the mediator (Scheme 1) [8]. However, it appears from our results that neither ABTS, SA nor AS acted as catalysts. These three mediators were consumed during the reaction, with a mediator/pollutant molar ratio in excess of unity. For AS and SA, a clear decrease in their concentration was observed as the reaction progressed, up to their complete disappearance (Figs. 1 C.2 and D.2). This consumption was independent of the pollutant concentration (similar decay rates were observed with or without the presence of SMX, Fig. S5, SI), suggesting that the pollutant was not involved in the disappearance of the mediators. The removal of SA and AS was thus probably caused by an irreversible oxidation by laccase. Although ABTS has been described as a catalytic mediator, with a constant recycling of its radical cation $\mathrm{ABTS}^{\bullet+}$ during the oxidation of various substrates [35], no catalytic reactions were observed in this study.

The disappearances of the mediators AS and SA (Figs. 1 C.2 and D.2) were proportional to the disappearance of SMX (linear correlation $r>0.99$ ) (Fig. S4, SI). This allowed determining the stoichiometry of the mediator-SMX reaction (molar ratio of the SMX oxidized relative to the mediator consumed). These ratios were $\mathrm{pH}$-dependent, varying from 1.7 ( $\mathrm{pH} 5-6$ ) to $2.4-2.5$ ( $\mathrm{pH} 3$ and 8 ), and from 2.4 ( $\mathrm{pH} \mathrm{6-7)}$ to $16(\mathrm{pH} 3)$, for SA and AS, respectively (Fig. 1E).

ABTS was not quantified during the reaction, but the radical cation $\mathrm{ABTS}^{\circ+}$ could be determined semi-quantitatively (HPLC-DAD signal intensity at $414 \mathrm{~nm}$ ). The disappearance of the $\mathrm{ABTS}^{\circ+}$ signal (Figs. 1 A.2 and B.2) was closely linked to the removal of SMX and IPN (Figs. 1 A.1 and B.1), suggesting that the radical cation was involved and consumed during the reaction. The possibility that ABTS $^{\bullet+}$ was reduced back to ABTS was ruled out as laccase activity stayed relatively constant until the end of the experiments, and thus ABTS was oxidized back to ABTS $^{*+}$ at a much higher rate (around $300 \mu \mathrm{M}$ per min) than its observed consumption (less than $1 \mu \mathrm{M}$ per min). The molar ratio of ABTS consumed per SMX oxidized was also pH-dependent, with 1.1 at $\mathrm{pH} 6$ and up to $2 \mathrm{~mol} / \mathrm{mol}$ at pH 4 (Fig. 1E), which is lower than for SA and AS. With IPN, this ratio could not be determined as a function of $\mathrm{pH}$, but at $\mathrm{pH} 5$, a molar ratio ABTS/IPN of $2.28( \pm 0.3)$ was found (based on Fig. $2 \mathrm{~B}$ ). IPN required thus 1.5 times more mediator than SMX for a similar extent of oxidation.

The increase in the mediator/pollutant ratio observed at low $\mathrm{pH}$, most pronounced for AS, was probably related to the very fast oxidation of the mediators at low $\mathrm{pH}$, leading to the rapid production of a high level of reactive mediator species. These reactive species reacted then probably more easily with each other than with the pollutants (present in lower concentrations), increasing therefore the mediator/pollutant ratio required at low $\mathrm{pH}$ (see Section 3.9 for further discussion).

\subsection{Effect of the concentrations of enzyme, mediators and pollutants on the pollutant oxidation rate}

To better understand the reactions involved in laccase-mediator systems, several experiments were performed in which either the mediator or the enzyme concentration was varied.

\subsubsection{Effect of the enzyme concentration}

It was observed that, at pH 5 (Fig. S6 A, SI), the oxidation of IPN with ABTS was not significantly influenced by a variation of the laccase activity by a factor of five (from 120 to $600 \mathrm{U}^{-1}$ ), while a strong influence on the rates was observed when reducing the mediator concentration by a factor of five (from 500 to $100 \mu \mathrm{M}$ ). Therefore, it can be assumed that at $\mathrm{pH} 5$ the rate-limiting step was not the oxidation of the mediator by laccase but the reaction of the oxidized mediator with the pollutant. However, at higher $\mathrm{pH}$, when the mediator oxidation by laccase becomes limiting, higher laccase activity is expected to increase the pollutant oxidation rate.

\subsubsection{Effect of the mediator and pollutant concentration}

A strong influence of the mediator concentration on the pollutant oxidation rates under acidic conditions was observed for both IPN and SMX (Figs. $2 \mathrm{~A}$ and B). As shown in Fig. 2C, the oxidation rates increased proportionally with increasing mediator concentrations, reaching a plateau at high mediator levels. The assumption behind this saturation effect (plateau) was that, at high mediator concentrations (and sufficient laccase activity), high levels of reactive radicals are quickly produced, with a tendency to react with each other (possibly already in the enzymatic pocket) rather than with the pollutants. However, this saturation effect was not observed when, instead of keeping the pollutant concentration constant, the pollutant level was varied in proportion to the mediator concentration so as to keep the mediator/pollutant ratio constant (Fig. 2C and Fig. S6 B, SI). In this case, a linear increase in the oxidation rate was observed as a function of the mediator (and pollutant) concentration, which was expected since the radical/pollutant ratio stayed constant.

In contrast to the results under acidic conditions, at $\mathrm{pH} \mathrm{7,} \mathrm{no}$ effect of mediator concentrations on the rate of SMX oxidation by the three mediators (Figs. 2 D-F) was observed. At the three mediator concentrations tested $(100,200$ and $500 \mu \mathrm{M})$, SMX was oxidised at the same constant rate (zero-order reaction) until all the mediator was consumed (Fig. S 5, SI). As laccase is several orders of magnitude less active in neutral-alkaline than in acidic conditions (Fig. 1F), this observation points towards a rate limitation of the oxidation of the mediator by laccase. Enzymatic reactions follow Michaelis-Menten kinetics. Therefore, the rate of the reaction does not vary with the mediator concentration when it is present at sufficiently high levels to saturate all the reactive sites of the enzymes. The radicals constantly produced are thus expected to react directly with SMX, leading to zero-order kinetics as long as sufficient mediator is present.

At a constant mediator/pollutant ratio (at $\mathrm{pH} \mathrm{5)}$ and with a sufficiently high mediator concentration, the relative pollutant removal rate appeared to be independent of the initial pollutant concentration (similar to first-order kinetics) (Fig. S 6 B, SI). Although this was not tested with low mediator/pollutant concentrations, it is expected that this independence would not be valid once the mediator concentration becomes lower than a certain threshold, related to the affinity constant of the enzyme for the mediator (Michaelis constant $K_{m}$ ). 
A

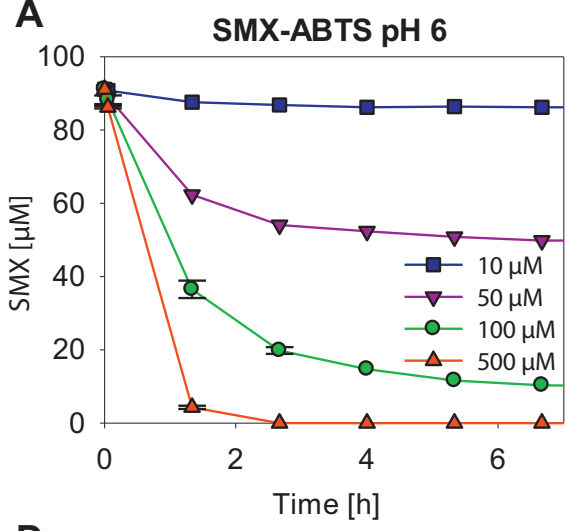

D

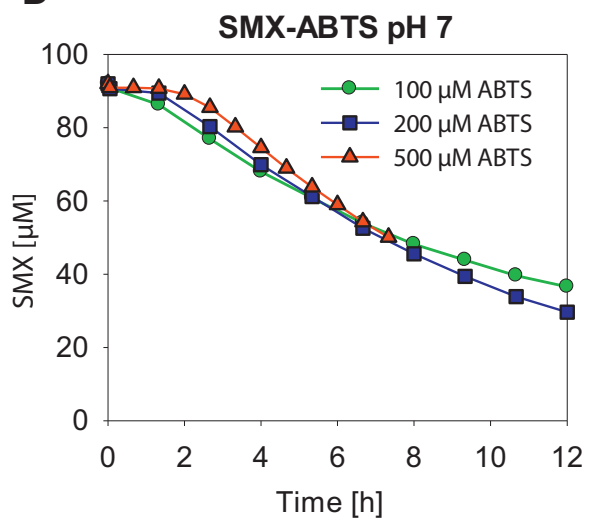

B

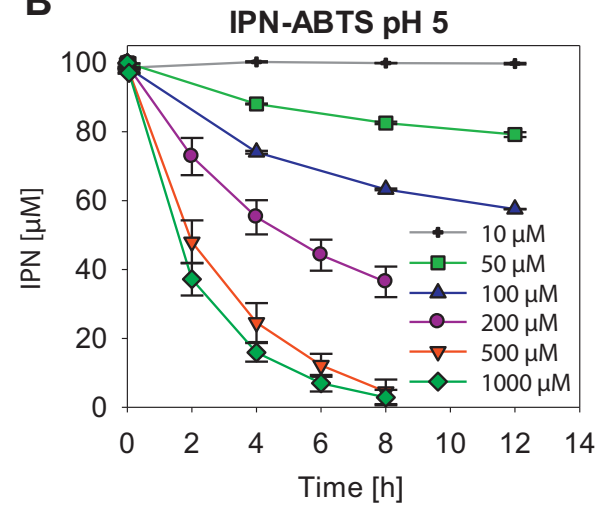

E

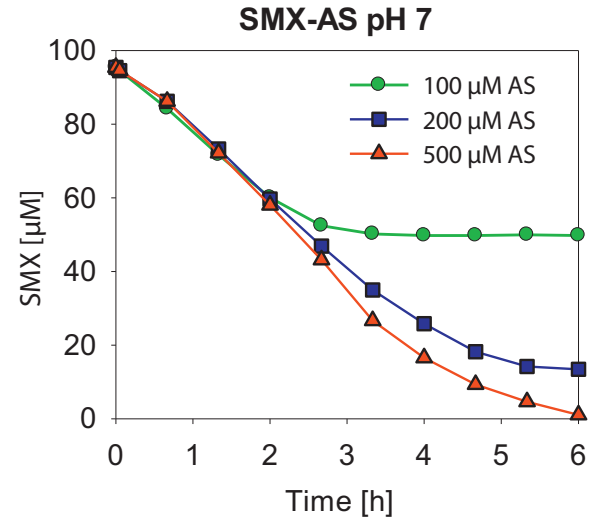

C

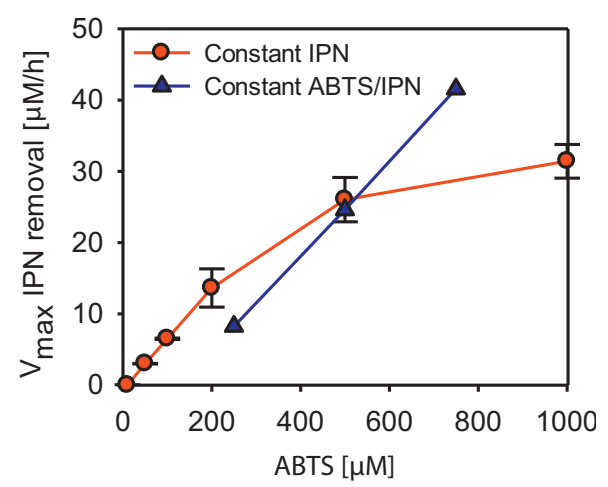

$\mathbf{F}$

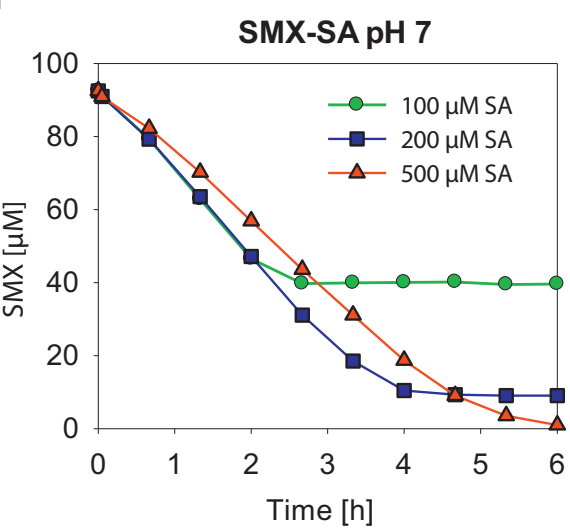

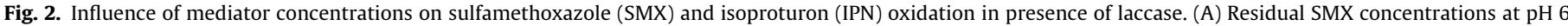

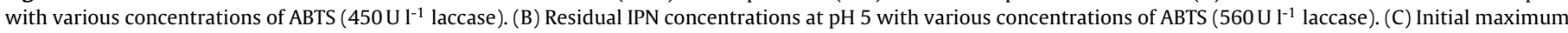

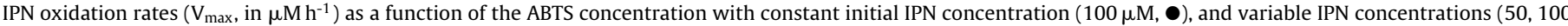

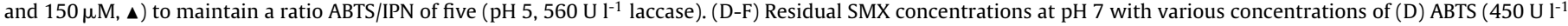

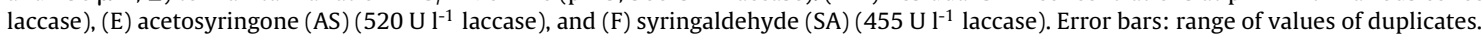

\subsection{Oxygen consumption during laccase-mediated reactions}

In the laccase-mediated reaction systems, around 0.25 mole of oxygen (one mole of electrons transferred) was consumed per mole of mediator (ABTS, AS and SA) oxidized during the initial phase of the reaction (when the mediator was still present at high concentration). Oxygen consumption stopped once SA was oxidized while, in presence of AS and ABTS, almost complete oxygen depletion was observed (Fig. S7, SI). This further oxygen consumption suggests that additional oxidation of the transformation products of AS and ABTS occurred slowly. In all cases, complete oxygen depletion was observed only after complete pollutant oxidation, suggesting no oxygen limitation in the reaction.

\subsection{Role of the ABTS radical cation for the oxidation of SMX or IPN}

For AS and SA, it is expected that the unstable and reactive phenoxy radicals generated during their oxidation by laccase (Fig. $\mathrm{S} 1, \mathrm{SI}$ ) are the reactive species causing the pollutant oxidation. For ABTS, it is not clear which reactive species are involved in pollutant oxidation. It is reported that $\mathrm{ABTS}^{\bullet+}$ can oxidize several compounds, mainly polyphenols, phenols or anilines $[35,36]$. To elucidate the fate of the selected target compounds, we investigated if $\mathrm{ABTS}^{\circ+}$ alone (oxidized chemically) could also oxidize SMX and IPN. As presented in Figs. S8 C and S9 C (SI), no SMX or IPN removal was observed with $\mathrm{ABTS}^{\circ+}$ alone, while addition of laccase $\left(280 \mathrm{U} \mathrm{I}^{-1}\right)$ in the same solution led to complete removal of both compounds in a few hours. Low laccase activity (7-9 $\left.\mathrm{U}^{-1}\right)$ enabled pollutant oxidation but when laccase was inhibited no degradation was observed with $\mathrm{ABTS}^{\circ+}$ (Figs. S8 A and S9 A, SI). This demonstrates that $\mathrm{ABTS}^{\bullet+}$ is not directly responsible for SMX or IPN oxidation and that laccase is necessary to catalyze this reaction.

To investigate if the reactive product responsible for pollutant degradation was formed during $\mathrm{ABTS}$ or $\mathrm{ABTS}^{\bullet+}$ oxidation by laccase, ABTS was chemically oxidized by chlorine to form a solution containing only $\mathrm{ABTS}^{\circ+}$, which was then used to treat the pollutants by addition of laccase. A comparison between the removal efficiencies of IPN and SMX by laccase with oxidized $\mathrm{ABTS}^{*+}$ or laccase with ABTS showed almost identical results (Fig. S10, SI), suggesting that the reactive species were formed from the reaction of $\mathrm{ABTS}^{\circ+}$ with laccase. Moreover, $\mathrm{ABTS}^{\circ+}$, which is quite stable in pure solution (half-life of $47 \mathrm{~h}$ at $20-23^{\circ} \mathrm{C}$ ) [21], was degraded in presence of the pollutants and laccase, at a rate strongly correlated with the removal rates of the micropollutants (Figs. 1 A.2 and B.2 and Fig. S8 B, SI). This suggests that laccase reacts with $\mathrm{ABTS}^{\circ+}$ producing reactive species, which in turn react with the pollutants.

A transformation product with a UV/vis spectrum similar to a degradation product of the ABTS di-cation $\left(\mathrm{ABTS}^{2+}\right)$ was detected in samples incubated with ABTS and laccase, suggesting an $\mathrm{ABTS}^{2+}$ formation (see Section 3.7). Although the direct oxidation of $\mathrm{ABTS}^{\circ+}$ (reduction potential $E^{0}=0.6 \mathrm{~V}$ ) to the stronger oxidant $\mathrm{ABTS}^{2+}$ $\left(E^{0}=1.1 \mathrm{~V}\right)$ by laccase ( $\mathrm{E}^{0}$ around $\left.0.8 \mathrm{~V}\right)$ is thermodynamically unfavourable, it was suggested that this reaction could slowly happen inside of the enzymatic pocket (the electrostatic interaction in the binding site may lower the reduction potential of the ABTS dication) [37]. ABTS $^{2+}$ is reported to oxidize several compounds such 

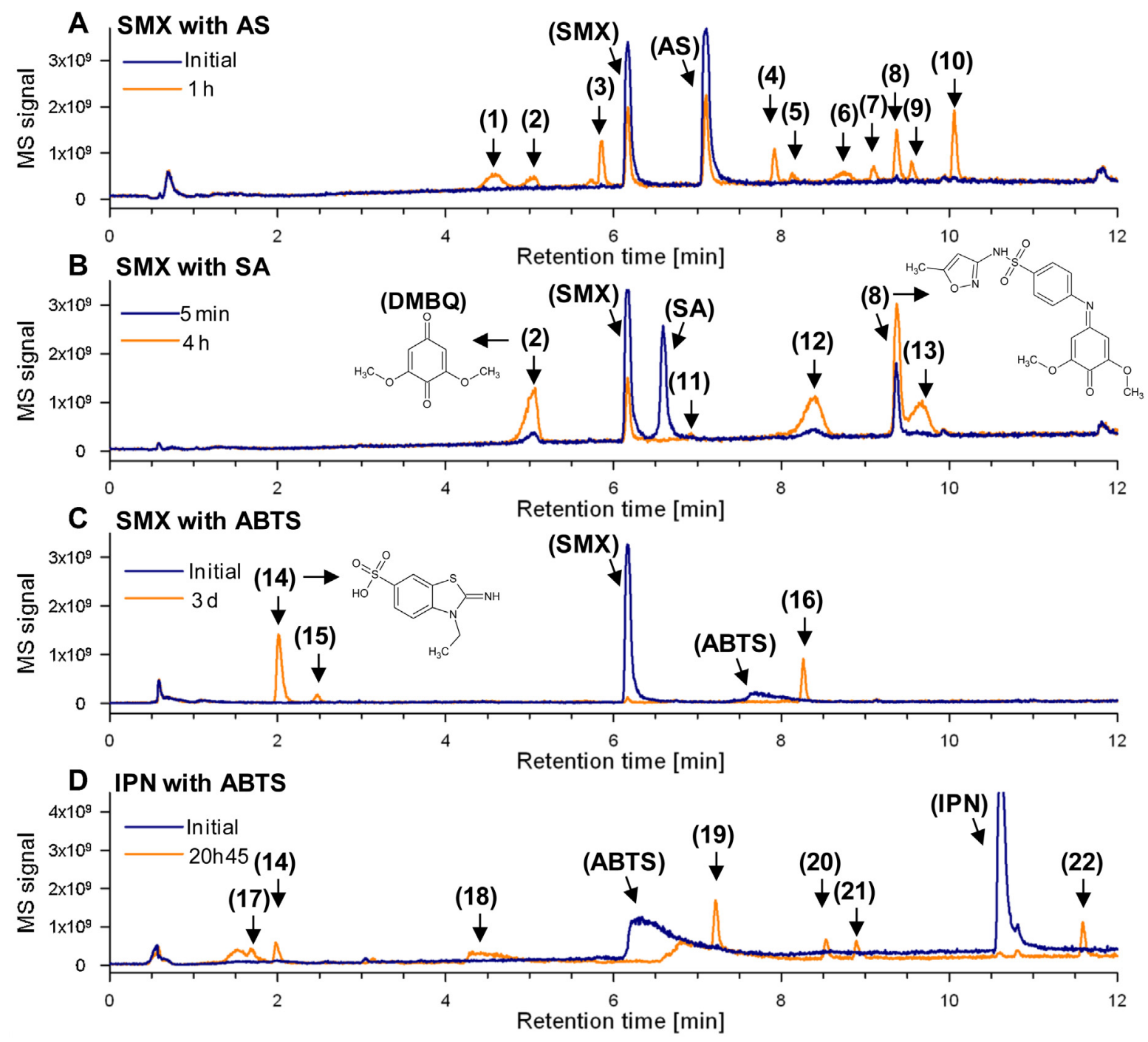

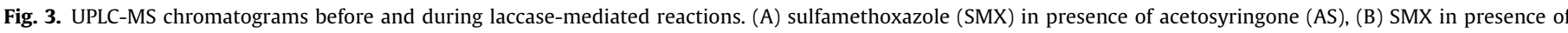

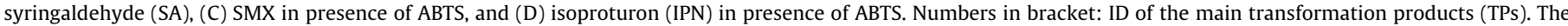

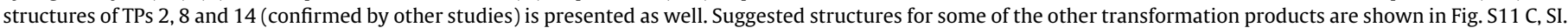

as aromatic alcohols that cannot be oxidized by ABTS $^{\bullet+}[38,39]$. ABTS $^{2+}$ (low solubility and very low stability in water) or one of its degradation products could therefore be the reactive species responsible for pollutant oxidation in the combined laccase/ABTS system $[37,39]$. A slow production of $\mathrm{ABTS}^{2+}$ may explain why the pollutant oxidation in the laccase/ABTS system takes several hours while the enzyme oxidizes ABTS completely to $\mathrm{ABTS}^{\bullet+}$ within a few minutes. These results indicate that in the present case, the real mediator is not ABTS but its radical cation ABTS $^{\circ+}$, which is oxidized by laccase to a reactive species with higher reduction potential (possibly $\mathrm{ABTS}^{2+}$ ) which, in turn, reacts with IPN or SMX.

\subsection{Characterization of the transformation products}

Oxidation by LMS does not lead to complete pollutant mineralization because laccase and the oxidized mediators react mainly with some specific (electron donating) moieties of organic compounds. As shown in the chromatograms in Fig. 3, several transformation products were detected by UPLC-MS for the reaction of SMX in presence of the three mediators and for the reaction of IPN in presence of ABTS.

\subsubsection{Transformation products formed in the laccase-AS-SMX} system

During SMX oxidation by laccase in presence of AS, 10 main transformation products were detected (ID number 1-10, Fig. 3A). Six of them had a molar mass higher than SMX or AS suggesting that they were coupling products (Table 1). Several products (1-3 and 6) were also generated during the oxidation of AS by laccase. Product 2, with a mass of $168 \mathrm{~g} \mathrm{~mol}^{-1}$ and a maximum $\mathrm{UV} /$ vis absorbance at $290 \mathrm{~nm}$ (Table S1, SI), was identified as 2,6dimethoxy-1,4-benzoquinone (DMBQ) (Fig. 3B), as observed in other studies [33,40]. Product 6 , with a mass of $332 \mathrm{~g} \mathrm{~mol}^{-1}$, is likely (but exact structure not confirmed) a dimeric product of AS, as proposed in Fig. S11, SI. Similar dimeric products were observed by Ibrahim et al. [40]. Products 4-5 and 7-10 were observed only when SMX was present. Product 8, with a mass of $403 \mathrm{~g} \mathrm{~mol}^{-1}$ and UV-vis absorption spectrum maxima at 200, 314 and $405 \mathrm{~nm}$, was identified based on similar studies [29,33] as a coupling product between DMBQ and SMX (Fig. 3B). The masses of products 5, 7 , 9 and 10 (Table 1 ) suggest that they were also coupling products between AS radicals and SMX (structure suggestion in Fig. S11, SI), as also proposed by Shi et al. [29]. All these transformation products appeared rapidly during the first hour of reaction, linked 
Table 1

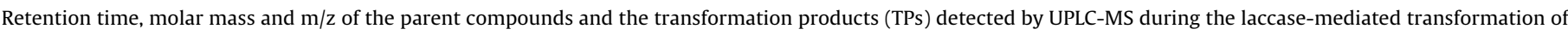

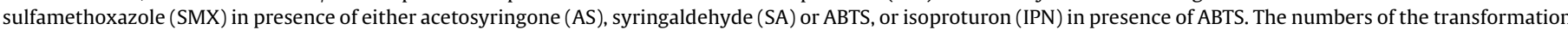
products correspond to Fig. 3. Structures of compounds with similar masses are suggested for some transformation products and presented in Fig. S11, SI.

\begin{tabular}{|c|c|c|c|c|c|}
\hline ID & Retention time [min] & Molar mass $[\mathrm{g} / \mathrm{mol}]^{\mathrm{a}}$ & $m / z$ of adducts ${ }^{b}$ & Types of product ${ }^{\mathrm{c}}$ & Structure propositon ${ }^{\mathrm{d}}$ \\
\hline \multicolumn{6}{|c|}{ Parents compounds } \\
\hline (AS) & 7.11 & 196 & $197+219$ & Acetosyringone & (AS) \\
\hline (SA) & 6.6 & 182 & $183+205$ & Syringaldehyde & (SA) \\
\hline (ABTS) & $6.44-7.69$ & 514 & $514+515+536+558$ & ABTS & (ABTS) \\
\hline$(\mathrm{SMX})$ & 6.19 & 253 & $254+276$ & Sulfamethoxazole & $(\mathrm{SMX})$ \\
\hline (IPN) & 10.62 & 206 & $207+229+435$ & Isoproturon & (IPN) \\
\hline \multicolumn{6}{|c|}{ Transformation products AS + SMX } \\
\hline (1) & 4.58 & 180 & $181+203$ & AS TP & - \\
\hline (2) & 5.05 & 168 & $169+191$ & 2,6-Dimethoxy-1,4-benzoquinone (DMBQ) & $(2)$ \\
\hline (3) & 5.85 & 182 & $183+205$ & AS TP & (V) \\
\hline (4) & 7.91 & 248 & $249+271+519$ & - & - \\
\hline (5) & 8.11 & 447 & $448+470$ & Coupling AS-SMX & (III) \\
\hline (6) & 8.77 & 332 & $333+355+687$ & Dimeric AS TP & (I) \\
\hline (7) & 9.1 & 415 & $416+438+454$ & Coupling AS-SMX & - \\
\hline (8) & 9.37 & 403 & $404+426$ & Coupling SMX-DMBQ & (8) \\
\hline (9) & 9.56 & 417 & $418+440$ & Coupling AS-SMX & (IV) \\
\hline (10) & 10.06 & 445 & $446+468$ & Coupling AS-SMX & - \\
\hline \multicolumn{6}{|c|}{ Transformation products SA+SMX } \\
\hline (2) & 5.05 & 168 & $169+191$ & 2,6-Dimethoxy-1,4-benzoquinone (DMBQ) & $(2)$ \\
\hline (11) & 6.93 & 281 & $282+304$ & - & - \\
\hline (12) & 8.38 & 318 & $319+341+659+351+373$ & Dimeric SA TP & (II) \\
\hline (8) & 9.37 & 403 & $404+426+829$ & Coupling SMX-DMBQ & (8) \\
\hline (13) & 9.66 & 348 & $349+371+367+381+719+403$ & - & - \\
\hline \multicolumn{6}{|c|}{ Transformation products $\mathrm{ABT}+\mathrm{SMX}$} \\
\hline (14) & 2.01 & 258 & $259+281$ & ABTS TP & $(14)$ \\
\hline (15) & 2.48 & 98 & 99 & SMX fragment & (VI) \\
\hline (16) & 8.26 & 238 & $239+261$ & SMX fragment & (VII) \\
\hline \multicolumn{6}{|c|}{ Transformation products ABTS + IPN } \\
\hline (17) & 1.69 & 273 & $274+296$ & ABTS TP & (VIII) \\
\hline (18) & 1.99 & 258 & $259+281$ & ABTS TP & $(14)$ \\
\hline (19) & 4.72 & 546 & $547+569$ & ABTS TP & - \\
\hline (20) & 7.23 & 222 & $223+245$ & Hydroxy-isoproturon & (IX) \\
\hline (21) & 8.56 & 445 & $446+468$ & Coupling IPN + fragments ABTS & - \\
\hline (22) & 8.9 & 447 & $448+470$ & Coupling IPN + fragments ABTS & - \\
\hline (23) & 11.61 & 232 & $233+255$ & - & - \\
\hline
\end{tabular}

a Molar mass $M$ deduced from the $m / z$ of the adducts.

b $m / z$ of ESI MS products with positive ion mode: $\mathrm{M}+\mathrm{H}$ : [M+1]; $\mathrm{M}+\mathrm{Na}:[\mathrm{M}+23] ; 2 \mathrm{M}+\mathrm{Na}$ : [2M+23]; $\mathrm{M}+\mathrm{CH}_{3} \mathrm{OH}:[\mathrm{M}+32] ; \mathrm{M}+\mathrm{NH} \mathrm{H}_{4}:[\mathrm{M}+18]$.

c Transformation products may come from the mediator degradation by laccase (also observed without pollutant), or by reaction with the pollutant. In italics : suggestion based on the mass of the by-product. (-): no suggestion.

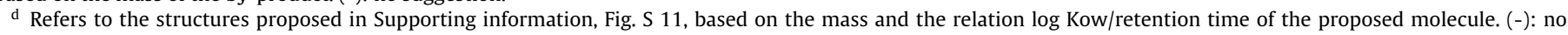
suggestion.

to the degradation of SMX and AS (Fig. S12, SI). Concentrations of products $2,4,6,7$ and 8 were stable for more than $72 \mathrm{~h}$. In contrast, products $1,3,5,9$ and 10 vanished within this time (Fig. S12, SI) suggesting that these products were either not stable or further oxidized by laccase, which is consistent with the additional oxygen consumption observed (cf. Section 3.5). After $72 \mathrm{~h}$, the two main (in signal intensity) products still present in solution were 2 and 8 (Fig. S12, SI).

\subsubsection{Transformation products formed in the laccase-SA-SMX} system

During SMX oxidation by laccase in presence of SA, only five main transformation products were detected (Table 1 ). Two of them were the same as found with AS, namely products 2 and 8 , which is not surprising because product 2 (DMBQ) is a typical product of SA oxidation [40]. These two dominant products were much more abundant with SA than with AS, with a 3.5-3.8 times higher signal intensity (Figs. 3A and B). The third most abundant transformation product was 12 , which is very likely a dimeric product of SA, with a structure similar to the dimeric AS (product 6) (Fig. S11, SI). Similar to AS, the five transformation products appeared during the first hour of reaction together with SMX and SA removal, and were then stable for more than $72 \mathrm{~h}$ (Fig. S12, SI).

\subsubsection{Transformation products formed in the laccase-ABTS-SMX system}

During SMX oxidation by laccase in presence of ABTS, only three transformation products were clearly visible (Fig. 3C, Table 1). Product 14 was also observed during ABTS oxidation by laccase without any pollutant and was identified as 3-ethyl-6-sulfonate benzothiazolinone imine, an ABTS fragment. Its chemical structure (Fig. 3C) was elucidated in other studies [41,42]. Products 15 and 16 were possibly, based on their mass and retention time (relative to their $\log K_{\mathrm{ow}}$ ), degradation products of SMX (Fig. S11, SI). No coupling products with a mass higher than the parent compounds were detected. The three products appeared gradually during $72 \mathrm{~h}$ in parallel to the disappearance of SMX and ABTS (sum of ABTS and $\mathrm{ABTS}^{\bullet+}$ ). The highest signal intensity was observed for the ABTS fragment 14, followed by SMX fragment 16.

\subsubsection{Transformation products formed in the laccase-ABTS-IPN system}

During IPN oxidation by laccase in presence of ABTS, 7 transformation products were detected (Fig. 3D, Table 1). Three of them $(14,17$ and 18$)$ were ABTS degradation products, also observed during ABTS oxidation without pollutant, and (at very low concentrations for 17 and 18) with SMX. Product 14 was the same 
A

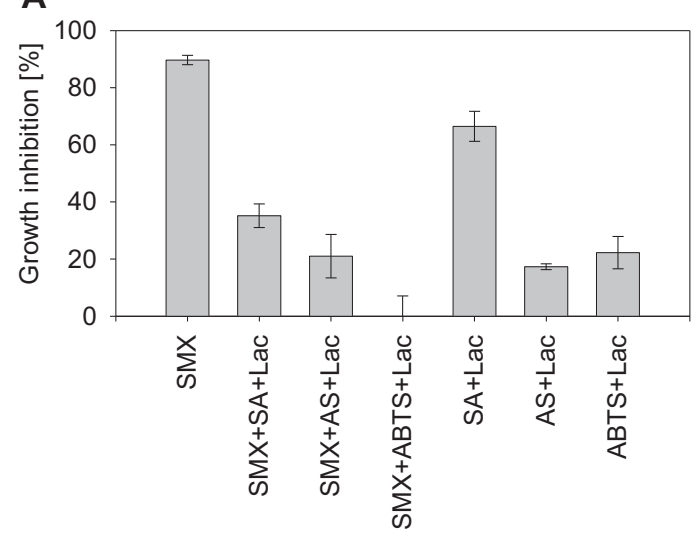

B

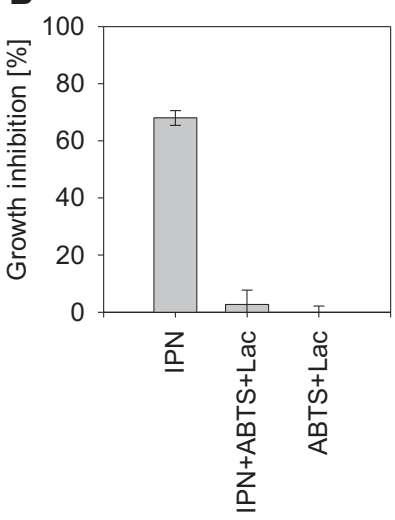

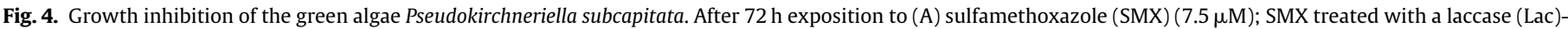

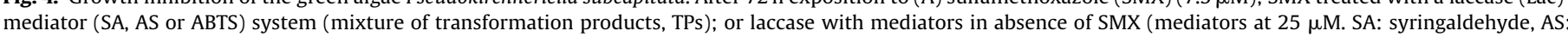

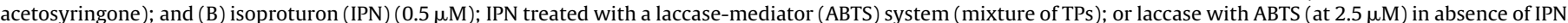
Average and standard deviation of triplicates.

ABTS fragment as detected in the ABTS-SMX system and product 17 was probably also an ABTS fragment (Fig. S11, SI). Product 18 had a higher mass ( $546 \mathrm{~g} \mathrm{~mol}^{-1}$ ) than ABTS $\left(514 \mathrm{~g} \mathrm{~mol}^{-1}\right)$, but could not be identified. Products 14 and 17 had UV/vis absorption spectra with maxima at 200, 258, 286, 294 and 218, 258, 284, $292 \mathrm{~nm}$ respectively (Table S1, SI). Similar absorption spectra $(220,254$, $284,292 \mathrm{~nm}$ ) were found for a decomposition product of ABTS $^{\circ+}$ in neutral-alkaline solutions ABTS $^{\circ+}$ is unstable under alkaline conditions) [39], suggesting that products 14 and 17 were related to $\mathrm{ABTS}^{\circ+}$ degradation. Product 18 had an absorption spectrum with maxima at 222, 264, 292, $300 \mathrm{~nm}$, which corresponds to the absorption spectrum of a (not clearly identified) decomposition product of $\mathrm{ABTS}^{2+}$ observed in other studies [39]. As proposed by Majcherczyk et al. [39] and as discussed before, this result may suggest that $\mathrm{ABTS}^{2+}$ was involved in the laccase-mediated reaction. Apart from product 17, which appeared rapidly (within $3 \mathrm{~h}$ ) and then disappeared slowly, both products 14 and 18 appeared gradually at a rate proportional to ABTS $\left(\right.$ and $\mathrm{ABTS}^{\circ+}$ ) degradation (Fig. S12, SI).

The four other detected transformation products (19-22) had all a mass higher than IPN, suggesting the potential formation of coupling products. None of them could be identified but, according to its mass and retention time, product 19 could possibly be a hydroxylated IPN (Fig. S11, SI).

\subsubsection{Influence of $\mathrm{pH}$ on the type of transformation products}

Several transformation products detected by UPLC-MS were related (by retention time comparisons) to transformation products observed by HPLC-UV/vis (chromatograms presented in Figs. S13-15, SI). Their relative abundance after complete reaction of the mediators with SMX could thus be determined at various $\mathrm{pH}$ values (Fig. S16, SI).

For SMX in the laccase-SA system (Fig. S16 A, SI), the abundance of the dimeric SA (product 12) observed at low $\mathrm{pH}(\mathrm{pH} 3)$ was a factor two higher compared to $\mathrm{pH} 4-7$, and almost no dimeric SA was detected at $\mathrm{pH}$ 8. In contrast, the coupling product SMX-DMBQ (product 8) was much more abundant (10 times) at $\mathrm{pH}$ 6-8 than at $\mathrm{pH}$ 3. The production of DMBQ (product 2 ) during SA oxidation was the highest at $\mathrm{pH} 6-7$.

Similar observations were made in the laccase-AS system in presence of SMX (Fig. S16 B, SI) where the coupling product SMXDMBQ (8) was observed in high abundance at $\mathrm{pH}$ 7-8 but almost not detected at $\mathrm{pH} 3-4$. The dimeric AS (product 6) was also almost absent at $\mathrm{pH} 8$ but present in high abundance at $\mathrm{pH} 3-6$. The production of DMBQ (product 2) during AS oxidation was highest at $\mathrm{pH}$ 6-7.

These results support the assumption that, at low $\mathrm{pH}$, the reactive mediator radicals are rapidly formed, favouring their coupling to form dimeric SA and AS rather than reacting with SMX. Under neutral to alkaline conditions, most of the reactive SA or AS radicals (slowly produced) react directly with SMX to form the coupling product SMX-DMBQ (product 8) or decompose to DMBQ (product 2).

The $\mathrm{pH}$ influenced also the relative product distribution in the laccase-ABTS system in the presence of SMX (Fig. S16 C, SI). Product 17 , an ABTS fragment, was more abundant at low $\mathrm{pH}$ while the ABTS fragment 14 was present at higher levels at a higher $\mathrm{pH}$. This suggests that ABTS decomposes into different products depending on the $\mathrm{pH}$. The abundance of the SMX fragment 16 was correlated with the percentage SMX removal observed at the different $\mathrm{pH}$ values.

\subsection{Toxicity of transformation products}

The evolution of the toxicity of the transformation products formed from IPN and SMX in laccase-mediated systems was assessed by ecotoxicity tests with green algae. After the treatment, both pollutants were not detected in the solutions $>99 \%$ abatement). The toxicity of the solutions containing mixtures of transformation products (Section 3.7) was compared to solutions containing the parent compounds, or the mediator oxidized by laccase in the absence of the pollutant (Fig. 4).

SMX at $7.5 \mu \mathrm{M}\left(1.9 \mathrm{mgl}^{-1}\right)$ inhibited $90 \%$ of algae growth compared to the control. Similar SMX toxicity to Pseudokirchneriella subcapitata were observed in other studies, with $\mathrm{EC}_{50}$ (concentration inhibiting 50\% of the growth) reported in the range of $0.15-0.5 \mathrm{mg} \mathrm{l}^{-1}$ [43] or at $1.9 \mathrm{mgl}^{-1}$ [24]. Laccasemediated treatments reduced this toxicity by $61 \%$ in presence of SA, $77 \%$ in presence of AS and $100 \%$ in presence of ABTS (Fig. 4A), demonstrating the much lower algal toxicity of the mixture of transformation products compared to the non-treated SMX.

To evaluate if the residual toxicity observed in presence of SA and AS was due to SMX transformation products or to mediator transformation products, the same bioassays were conducted in absence of SMX. High algae growth inhibition (66\%) was observed in the solution with SA $(25 \mu \mathrm{M})$, and lower but significant inhibition was observed with laccase-induced oxidation of AS and ABTS (17 and $22 \%$, respectively). Especially with SA, the residual toxicity was higher in absence than in presence of SMX transformation 

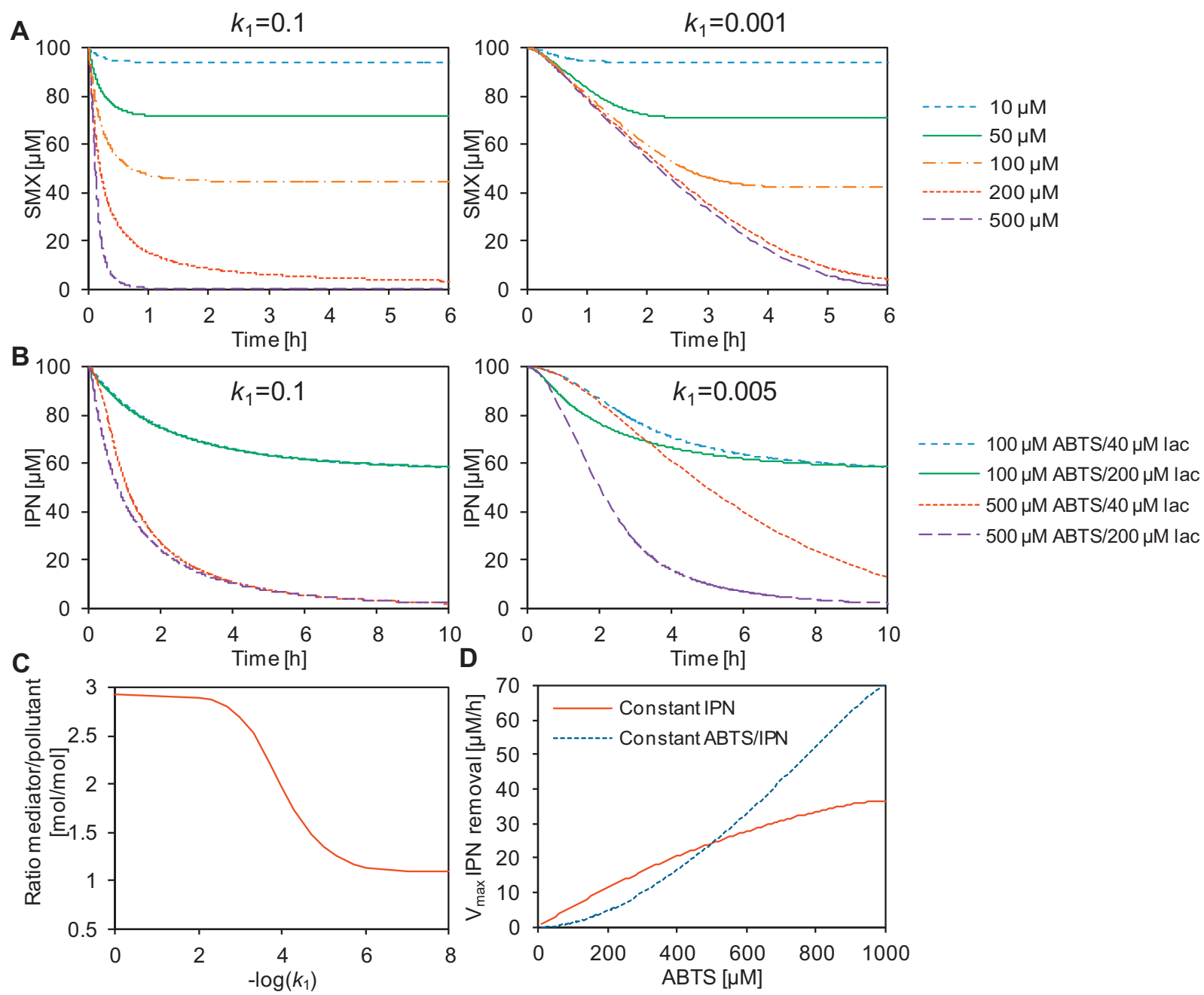

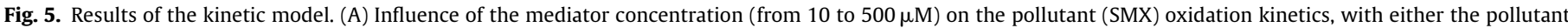

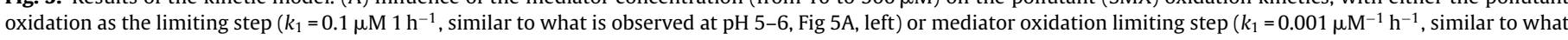

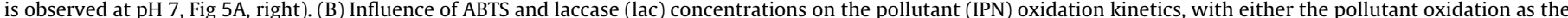

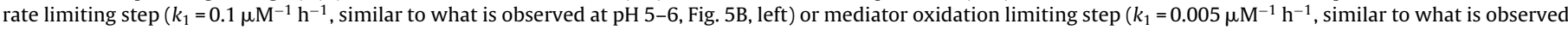

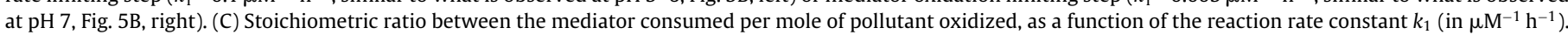

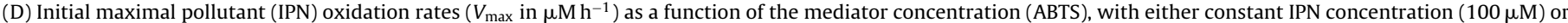
constant ABTS/IPN ratio $\left(5 \mathrm{~mol} \mathrm{~mol}^{-1}\right)$. The modeling parameters are presented in Table S2, SI.

products. The product 2 (DMBQ) was produced in lower quantities in presence of SMX (Fig. S14, SI) (due to the reaction of the SA phenoxy radical with the pollutant), and also present in lower concentrations (2-8 times) in the oxidized AS solution (which was less toxic). This suggests that DMBQ might be responsible for a part of the toxicity observed with SA and AS. The toxicity of the oxidized SA was also reported in other studies (20\% bacterial inhibition at $0.25 \mu \mathrm{M}$ ) [32]. Mediator transformation products were thus probably the reason for the residual toxicity observed after complete SMX oxidation. As the $\mathrm{pH}$ influences the relative abundance of each product (Section 3.7.5), different toxicity may thus also be observed at various $\mathrm{pH}$ values, with possibly lower toxicity at alkaline $\mathrm{pH}$ (lower concentrations of DMBQ).

IPN at $0.5 \mu \mathrm{M}\left(103 \mu \mathrm{g} \mathrm{l}^{-1}\right)$ inhibited $68 \%$ ( $\left.\pm 3 \%\right)$ of algae growth (Fig. 4B), which is similar to what was reported by Pavlic et al. [25] (70\% inhibition at $\left.100 \mu \mathrm{gl}^{-1}\right)$. After the treatment in the laccase-ABTS system, more than $95 \%$ of this toxicity disappeared, showing the very low toxicity of the transformation product mixture compared to IPN.

These results show that laccase-mediated reactions can significantly reduce toxicity of SMX and IPN to algae (among the most sensitive organisms for these pollutants) despite the formation of several transformation products. The synthetic mediator ABTS was most efficient with almost complete IPN and SMX toxicity removal, while residual toxicity was still observed with the natural mediators AS and SA. Laccase-mediated systems appear thus to be an interesting way to decontaminate effluents, which are toxic to sensitive aquatic organisms. However, precautions must be taken when treating effluents with low toxicity because oxidized mediators (especially SA) may generate significant residual toxicity at low concentrations $(<25 \mu \mathrm{M})$.

\subsection{Mechanistic aspects of laccase-mediated reactions}

The ideal scheme of laccase-mediated reactions where the mediator is continuously recycled during the redox process (Scheme 1) does not correspond to the observations in this study. Based on our results, an alternative laccase-mediated oxidation model is proposed (Scheme 2).

As illustrated in Scheme 2 and described in Eqs. (1)-(4), our results suggest that the mediator (med) is oxidized by laccase (lac) to reactive radicals $\left(R^{\bullet}\right)$ (Eq. (1)) that will either react by a 


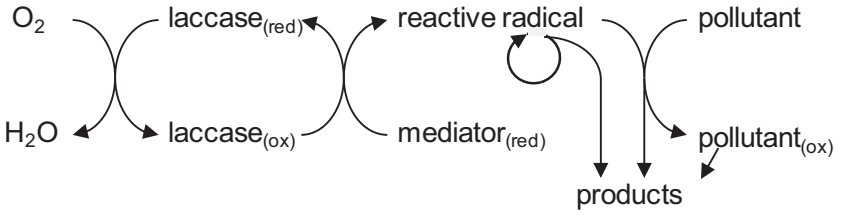

Scheme 2. Proposition of a laccase-mediator reaction model.

radical-radical coupling reaction, producing products $P_{1}$ (such as dimeric AS and SA) (Eq. (2)), further react to more stable products $\left(P_{2}\right)$ (e.g., 2,6 DMBQ for AS and SA) (Eq. (3)), or react with other compounds present in the solution, such as the pollutants (poll), at a stoichiometric ratio $a$ (number of moles of radical needed to oxidize one mole of pollutant) to produce products $P_{3}$ (e.g., oxidation products of SMX or coupling products SMX-DMBQ) (Eq. (4)). $k_{1}-k_{4}$ are the rate constants for Reactions (1)-(4), respectively. This mechanistic description is coherent with the nature of the transformation products detected (Section 3.7) (illustration for SA and SMX in Fig. S17, SI).

$\mathrm{lac}+\mathrm{med}+\frac{1}{4} \mathrm{O}_{2} \stackrel{k_{1}}{\rightarrow} \mathrm{lac}+R^{\bullet}+\frac{1}{2} \mathrm{H}_{2} \mathrm{O}$

$R^{\bullet}+R^{\bullet} \stackrel{k_{2}}{\rightarrow} P_{1}$

$R^{\bullet} \stackrel{k_{3}}{\rightarrow} P_{2}$

$R^{\bullet}+\frac{1}{\mathrm{a}} \operatorname{poll}^{k_{4}} \rightarrow P_{3}$

Based on this reaction model, a kinetic model was established (Section 13, SI) and used to simulate the behavior of the laccasemediated reactions under various conditions. The results of selected simulations are presented in Fig. 5.

Both the effect of the mediator concentrations on the oxidation rates of SMX under acidic conditions and the absence of such an effect under neutral conditions (Fig. 2) could be correctly reproduced by the model by varying the rate constant $k_{1}$ (Eq. (1)) (Fig. 5A).

As discussed before, under acidic conditions, increasing the mediator concentration increased the pollutant oxidation rate, reaching progressively a plateau (a maximum) at high mediator concentrations (Fig. 2C). This saturation effect was attributed to significant cross-reactions between the radicals produced in high quantities (reactions of Eq. (2) favoured over Eq. (4)), and were correctly reproduced by the model (Fig. 5D). This saturation effect was not observed with constant mediator/pollutant ratios (Fig. 2C), a phenomenon confirmed with the model (Fig. 5D). Indeed, reaction rates of Eq. (2) and Eq. (4) were enhanced in the same way with the parallel increase in both mediator and pollutant concentrations.

As discussed before, under acidic conditions a strong increase in laccase activity (up to a factor 5 ) did not significantly increase the pollutant oxidation rates, while an increase in the mediator concentration strongly enhanced the reaction (Fig. S6 A, SI), suggesting that the oxidation of the mediator by laccase was not the limiting step. This phenomenon was reproduced with the model by choosing a relatively high (non-limiting) reaction rate $k_{1}$ (Fig. 5B). At higher $\mathrm{pH}$ (lower $k_{1}$ ), when the mediator oxidation by laccase becomes rate-limiting, the model shows that a higher laccase activity is necessary to increase the pollutant oxidation rate (Fig. 5B).

The increase in the required mediator/pollutant ratio observed at low pH (Fig. 1E) was reproduced with the model by increasing the reaction rate constant $k_{1}$ (as observed at low pH) (Fig. 5C). Indeed, at low $k_{1}$ values $\left(-\log \left(k_{1}\right)>5\right)$, the reaction is limited by the oxidation of the mediator by laccase (similar to the observations at neutral-alkaline $\mathrm{pH}$ ) and the ratio mediator/pollutant is close to the minimum set for this simulation (ratio of 1 ). As $k_{1}$ increases $\left(-\log \left(k_{1}\right)<5\right)$, corresponding to a decrease in $\mathrm{pH}$, the reaction becomes more and more limited by the oxidation of the pollutant by the radical $\left(k_{4}\right)$. The radicals, rapidly produced, tend to accumulate in the solution and to react with each other or be further transformed ( $k_{2}$ and $k_{3}$ ) rather than reacting with the pollutant. This leads to an increase in the mediator/pollutant ratio.

The proposed model was able to qualitatively reproduce all the different scenarios observed in the experiments, confirming that the mechanistic description proposed is adequate to describe laccase-mediated reactions.

\subsection{Practical implications}

This study highlights several points regarding the potential application of laccase-mediated systems for the treatment of micropollutants in contaminated waters. In particular, it is possible to assess the feasibility of treating very low pollutant concentrations in wastewater and how to enhance oxidation rates.

\subsubsection{Treatment of very low pollutant concentrations}

The model developed allowed assessing the oxidation kinetics for very low concentrations of pollutants. The time required to remove $90 \%$ of a (fictive) pollutant was modelled as a function of the pollutant concentration using two scenarios: (i) constant ratio mediator/pollutant (ratio of five), and (ii) constant mediator concentration (at $500 \mu \mathrm{M}$ ) (Fig. 6).

In the first scenario, when the pollutant, and therefore the mediator, were present at high concentrations ( $>100$ and $500 \mu \mathrm{M}$,
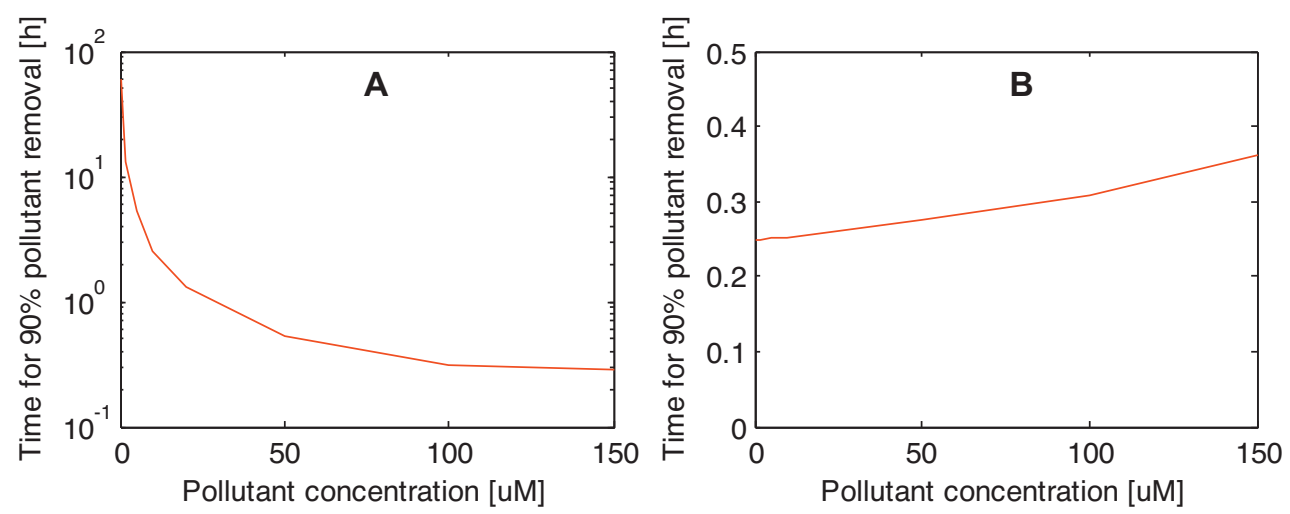

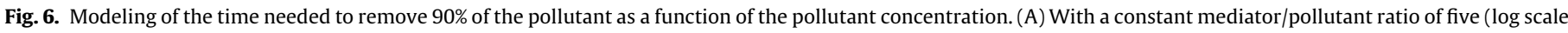
for the $y$-axis). (B) With a constant mediator concentration of $500 \mu \mathrm{M}$. The modeling parameters are presented in Table S2, SI. 
respectively), the removal time was independent of the pollutant concentration (similar to the experimental results, Fig. S6 B). But, as shown in Fig. 6A, this was valid only for pollutant concentrations $>100 \mu \mathrm{M}$, corresponding to mediator concentrations $>50$ times the affinity constant of the enzyme for the mediator (Michaelis constant $K_{m}$, chosen at $10 \mu \mathrm{M}$ ). At lower pollutant (and therefore mediator) concentrations, the time required to remove $90 \%$ of the pollutant was predicted to increase by a factor around 10 every time the mediator concentration was divided by $10(18 \mathrm{~min}$ at $500 \mu \mathrm{M}$ up to $60 \mathrm{~h}$ at $2.5 \mu \mathrm{M}$ ). The relatively low affinity of the enzyme for the mediator implies that adding mediator at concentrations lower than the $K_{m}$ of the enzyme (which is for instance around $20 \mu \mathrm{M}$ for ABTS with this laccase, Fig. S18, SI) will require excessively long reaction times ( $>50$ times the minimum).

When the mediator concentration was kept constant (at a value far above the $K_{m}$, scenario 2), only a limited effect of the pollutant concentration on the removal time was predicted (Fig. 6B), showing the possibility, with high mediator doses, to treat pollutants rapidly even at very low pollutant concentrations.

Treatment of low pollutant concentrations (e.g., $1 \mu \mathrm{gl}^{-1}$ or $0.005 \mu \mathrm{M}$ ) will thus require very high mediator/pollutant ratios to avoid too long reaction times (e.g., a ratio above 4000 to keep a mediator concentration above $20 \mu \mathrm{M}$ ), which may lead to increase the toxicity of the water due to the release of high quantities of mediator transformation products.

\subsubsection{Strategy to improve oxidation rates}

The results presented above show that, depending on the $\mathrm{pH}$, different strategies have to be applied to optimize the rate of pollutant degradation in laccase-mediated processes. If the reaction is limited by the oxidation of a pollutant by the radical $(\mathrm{pH}<6)$, increasing the laccase activity has almost no effect and the best strategy is to increase the mediator concentration. However, this increase should stay below a certain threshold (mediator/pollutant ratio $<10$ ) because at higher mediator concentrations reaction rates will reach a plateau due to high losses of the radicals formed from the laccase-mediator reaction (self-reactions). If the reaction is limited by the mediator oxidation by laccase $(\mathrm{pH}>7)$, increasing the mediator concentration will not affect the oxidation rate of the target compound, as long as the mediator concentration is $\mathbf{5 0}$ times the $K_{m}$ value of the enzyme. The strategy in this case is thus to increase the laccase activity. When both reactions are limiting ( $\mathrm{pH}$ 6-7), an increase in both laccase and mediator concentrations should be considered.

\subsubsection{Limitations of laccase-mediator systems for municipal wastewater}

Despite fast oxidation of SMX and IPN in laccase-mediated systems and their related toxicity removal, addition of laccase and mediators in real treatment systems to increase micropollutant removal faces many limitations in terms of its feasibility: (i) The high concentration of mediator required $(>10 \mu \mathrm{M})$ due to mediator consumption during the reaction, the relatively low affinity of laccase for the mediator and the possible loss of radicals by reaction with other matrix components. (ii) The potential formation of toxic transformation products due to the oxidation of the mediator. (iii) The formation of several mediator transformation products at concentrations possibly much higher than the target pollutant. Therefore, an application of LMS to treat municipal wastewater with very low micropollutant concentrations appears to be unrealistic. However, LMS may be an option for treatment of industrial wastewater that contains concentrated and toxic pollutants, such as effluents of pharmaceutical or pesticide industries. Indeed, in contrast to biological water treatment, LMS are not subject to intoxication and may be used to reduce the toxicity of highly polluted effluents, prior to further biological treatment of the transformation products.

\section{Conclusions}

The use of laccase-mediator systems effectively transformed IPN (with ABTS) and SMX (with ABTS, AS ad SA) to less toxic transformation products, consisting mostly of coupling products. The $\mathrm{pH}$ had a strong influence on the oxidation kinetics (faster at low $\mathrm{pH}$ ) and on the required mediator/pollutant ratio (higher at low $\mathrm{pH}$ ). Indeed, the three mediators tested did not act as catalysts and were therefore consumed in the process. Our results suggest that laccase oxidizes mediators to reactive radicals, which either spontaneously degrade into more stable products, react with each other (coupling reactions between radicals) or with the pollutants. Despite the requirement of high amount of mediators, LMS appears to be a potentially promising technology to treat concentrated and toxic effluents.

\section{Acknowledgements}

We thank Nathalie Chèvre (UNIL) for helpful discussions on the toxicity tests, Nuria Montpart (UAB) for her advices regarding the modelling part and Dominique Granjean (EPFL) for the technical support with the UPLC-MS. This study was funded by internal EPFL sources.

\section{Appendix A. Supplementary data}

Supplementary data associated with this article can be found, in the online version, at http://dx.doi.org/10.1016/j.bej.2015.06.008

\section{References}

[1] J. Margot, C. Kienle, A. Magnet, M. Weil, L. Rossi, L.F. de Alencastro, C. Abegglen, D. Thonney, N. Chèvre, M. Schärer, D.A. Barry, Treatment of micropollutants in municipal wastewater: ozone or powdered activated carbon? Sci. Total Environ. 461-462 (2013) 480-498.

[2] C.R. Tyler, S. Jobling, Roach, sex, and gender-bending chemicals: the feminization of wild fish in English rivers, Bioscience 58 (2008) 1051-1059.

[3] R. Petrie, A review on emerging contaminants in wastewaters and the environment: current knowledge, understudied areas and recommendations for future monitoring, Water Res. (2014), http://dx.doi.org/10.1016/j.watres. 2014.08.053, In press.

[4] P.L. Gillis, F. Gagné, R. McInnis, T.M. Hooey, E.S. Choy, C. André, M.E. Hoque, C.D. Metcalfe, The impact of municipal wastewater effluent on field-deployed freshwater mussels in the Grand River (Ontario, Canada), Environ. Toxicol. Chem. 33 (2014) 134-143.

[5] G.S. Nyanhongo, G. Guebitz, P. Sukyai, C. Leitner, D. Haltrich, R. Ludwig, Oxidoreductases from Trametes spp. in biotechnology: a wealth of catalytic activity, Food Technol. Biotechnol. 45 (2007) 250-268.

[6] S. Yang, F.I. Hai, L.D. Nghiem, W.E. Price, F. Roddick, M.T. Moreira, S.F. Magram, Understanding the factors controlling the removal of trace organic contaminants by white-rot fungi and their lignin modifying enzymes: a critical review, Bioresour. Technol. 141 (2013) 97-108.

[7] M. Husain, Q. Husain, Applications of redox mediators in the treatment of organic pollutants by using oxidoreductive enzymes: a review, Crit. Rev. Env. Sci. Technol. 38 (2008) 1-42.

[8] M. Fabbrini, C. Galli, P. Gentili, Comparing the catalytic efficiency of some mediators of laccase, J. Mol. Catal. B: Enzym. 16 (2002) 231-240.

[9] K. González Arzola, M.C. Arévalo, M.A. Falcón, Catalytic efficiency of natural and synthetic compounds used as laccase-mediators in oxidising veratryl alcohol and a kraft lignin, estimated by electrochemical analysis, Electrochim. Acta 54 (2009) 2621-2629.

[10] H.A. Garcia, C.M. Hoffman, K.A. Kinney, D.F. Lawler, Laccase-catalyzed oxidation of oxybenzone in municipal wastewater primary effluent, Water Res. 45 (2011) 1921-1932.

[11] M. Auriol, Y. Filali-Meknassi, R.D. Tyagi, C.D. Adams, Laccase-catalyzed conversion of natural and synthetic hormones from a municipal wastewater, Water Res. 41 (2007) 3281-3288.

[12] K. Murugesan, Y.-Y. Chang, Y.-M. Kim, J.-R. Jeon, E.-J. Kim, Y.-S. Chang, Enhanced transformation of triclosan by laccase in the presence of redox mediators, Water Res. 44 (2010) 298-308. 
[13] N.H. Tran, J. Hu, T. Urase, Removal of the insect repellent $\mathrm{N}, \mathrm{N}$-diethyl-m-toluamide (DEET) by laccase-mediated systems, Bioresour. Technol. 147 (2013) 667-671.

[14] L.N. Nguyen, F.I. Hai, J. Kang, F.D.L. Leusch, F. Roddick, S.F. Magram, W.E. Price, L.D. Nghiem, Enhancement of trace organic contaminant degradation by crude enzyme extract from Trametes versicolor culture: effect of mediator type and concentration, J. Taiwan Inst. Chem. Eng. 45 (2014) 1855-1862.

[15] F. Medina, S. Aguila, M.C. Baratto, A. Martorana, R. Basosi, J.B. Alderete, R. Vazquez-Duhalt, Prediction model based on decision tree analysis for laccase mediators, Enzyme Microb. Technol. 52 (2013) 68-76.

[16] A. Martorana, L. Sorace, H. Boer, R. Vazquez-Duhalt, R. Basosi, M.C. Baratto, A spectroscopic characterization of a phenolic natural mediator in the laccase biocatalytic reaction, J. Mol. Catal. B: Enzym. 97 (2013) 203-208.

[17] R. Kase, R.I.L. Eggen, M. Junghans, C. Götz, J. Hollender, Assessment of micropollutants from municipal wastewater - combination of exposure and ecotoxicological effect data for Switzerland, in: F. Einschlag (Ed.), Waste Water - Evaluation and Management, In Tech, Rijeka, Croatia, 2011, pp. 31-54.

[18] F. Bonvin, A.M. Razmi, D.A. Barry, T. Kohn, Micropollutant dynamics in vidy bay - a coupled hydrodynamic-photolysis model to assess the spatial extent of ecotoxicological risk, Environ. Sci. Technol. 47 (2013) 9207-9216.

[19] EC, Directive 2013/39/EU of the European Parliament and of the Council amending Directives 2000/60/EC and 2008/105/EC as regards priority substances in the field of water policy, 2013. http://eur-lex.europa.eu/ LexUriServ/LexUriServ.do?uri=0J:L\%202013.226:0001:0017:EN:PDF (last accessed 20.02.14)

[20] C.S. Furman, D.W. Margerum, Mechanism of chlorine dioxide and chlorate ion formation from the reaction of hypobromous acid and chlorite ion, Inorg. Chem. 37 (1998) 4321-4327.

[21] U. Pinkernell, B. Nowack, H. Gallard, U. Von Gunten, Methods for the photometric determination of reactive bromine and chlorine species with ABTS, Water Res. 34 (2000) 4343-4350.

[22] R.E. Childs, W.G. Bardsley, The steady state kinetics of peroxidase with 2,2 'azino di (3 ethylbenzthiazoline 6 sulphonic acid) as chromogen, Biochem. J. 145 (1975) 93-103.

[23] J. Margot, J. Maillard, L. Rossi, D.A. Barry, C. Holliger, Influence of treatment conditions on the oxidation of micropollutants by Trametes versicolor laccase, New Biotechnol. 30 (2013) 803-813.

[24] L.H. Yang, G.G. Ying, H.C. Su, J.L. Stauber, M.S. Adams, M.T. Binet, Growth-inhibiting effects of 12 antibacterial agents and their mixtures on the freshwater microalga Pseudokirchneriella subcapitata, Environ. Toxicol. Chem. 27 (2008) 1201-1208.

[25] Ž. Pavlić, B. Stjepanović, J. Horvatić, V. Peršić, D. Puntarić, J. Čulig, Comparative sensitivity of green algae to herbicides using erlenmeyer flask and microplate growth-inhibition assays, Bull. Environ. Contam. Toxicol. 76 (2006) 883-890.

[26] OECD, OECD Guidelines for testing of chemicals. Test No. 201: Freshwate Alga and Cyanobacteria, Growth Inhibition Test, 2011, pp. 25: http://www. oecd-ilibrary.org/environment/test-no-201-alga-growth-inhibition-test. 9789264069923-en, (last accessed 14.08.14).

[27] N. Vallotton, R.I.L. Eggen, N. Chèvre, Effect of sequential isoproturon pulse exposure on scenedesmus vacuolatus, Arch. Environ. Contam. Toxicol. 56 (2009) 442-449.
[28] S. Daouk, P.J. Copin, L. Rossi, N. Chèvre, H.-R. Pfeifer, Dynamics and environmental risk assessment of the herbicide glyphosate and its metabolite AMPA in a small vineyard river of the Lake Geneva catchment, Environ. Toxicol. Chem. 32 (2013) 2035-2044.

[29] L. Shi, F. Ma, Y. Han, X. Zhang, H. Yu, Removal of sulfonamide antibiotics by oriented immobilized laccase on $\mathrm{Fe}_{3} \mathrm{O}_{4}$ nanoparticles with natural mediators, J. Hazard. Mater. 279 (2014) 203-211.

[30] X.1. Guo, Z.w. Zhu, H.l. Li, Biodegradation of sulfamethoxazole by Phanerochaete chrysosporium, J. Mol. Liq. 198 (2014) 169-172.

[31] S. Yang, F.I. Hai, L.D. Nghiem, F. Roddick, W.E. Price, Removal of trace organic contaminants by nitrifying activated sludge and whole-cell and crude enzyme extract of Trametes versicolor, Water Sci. Technol. 67 (2013) 1216-1223.

[32] L.N. Nguyen, F.I. Hai, W.E. Price, F.D.L. Leusch, F. Roddick, H.H. Ngo, W. Guo, S.F. Magram, L.D. Nghiem, The effects of mediator and granular activated carbon addition on degradation of trace organic contaminants by an enzymatic membrane reactor, Bioresour. Technol. 167 (2014) 169-177.

[33] S.-S. Weng, K.-L. Ku, H.-T. Lai, The implication of mediators for enhancement of laccase oxidation of sulfonamide antibiotics, Bioresour. Technol. 113 (2012) 259-264.

[34] J. Margot, C. Bennati-Granier, J. Maillard, P. Blánquez, D.A. Barry, C. Holliger, Bacterial versus fungal laccase: potential for micropollutant degradation, AMB Express 3 (2013) 1-14

[35] M. Solís-Oba, V.M. Ugalde-Saldívar, I. González, G. Viniegra-González, An electrochemical-spectrophotometrical study of the oxidized forms of the mediator 2,2'-azino-bis-(3-ethylbenzothiazoline-6-sulfonic acid) produced by immobilized laccase, J. Electroanal. Chem. 579 (2005) 59-66.

[36] A.M. Osman, K.K.Y. Wong, A. Fernyhough, ABTS radical-driven oxidation of polyphenols: isolation and structural elucidation of covalent adducts, Biochem. Biophys. Res. Commun. 346 (2006) 321-329.

[37] B. Branchi, C. Galli, P. Gentili, Kinetics of oxidation of benzyl alcohols by the dication and radical cation of ABTS. Comparison with laccase-ABTS oxidations: an apparent paradox, Org. Biomol. Chem. 3 (2005) 2604-2614.

[38] R. Bourbonnais, D. Leech, M.G. Paice, Electrochemical analysis of the interactions of laccase mediators with lignin model compounds, Biochim. Biophys. Acta 1379 (1998) 381-390.

[39] A. Majcherczyk, C. Johannes, A. Huttermann, Oxidation of aromatic alcohols by laccase from Trametes versicolor mediated by the 2,2'-azino-bis-(3-ethylbenzothiazoline-6-sulphonic acid) cation radical and dication, Appl. Microbiol. Biotechnol. 51 (1999) 267-276.

[40] V. Ibrahim, N. Volkova, S.H. Pyo, G. Mamo, R. Hatti-Kaul, Laccase catalysed modification of lignin subunits and coupling to $p$-aminobenzoic acid, J. Mol Catal. B: Enzym. 97 (2013) 45-53.

[41] A.M. Osman, K.K.Y. Wong, S.J. Hill, A. Fernyhough, Isolation and the characterization of the degradation products of the mediator ABTS-derived radicals formed upon reaction with polyphenols, Biochem. Biophys. Res. Commun. 340 (2006) 597-603.

[42] A. Marjasvaara, J. Jänis, P. Vainiotalo, Oxidation of a laccase mediator ABTS as studied by ESI-FTICR mass spectrometry, J. Mass Spectrom. 43 (2008) 470-477.

[43] M.J. García-Galán, M. Silvia Díaz-Cruz, D. Barceló, Combining chemical analysis and ecotoxicity to determine environmental exposure and to assess risk from sulfonamides, Trends Anal. Chem. 28 (2009) 804-819. 